Département de sciences économiques

9816

\title{
Sampling Interval and estimated Betas : Implications for the Presence of Transitory Components in Stock Prices
}

PERRON, Pierre

VODOUNOU, Cosme 


\section{Département de sciences économiques}

Université de Montréal

Faculté des arts et des sciences

C.P. 6128, succursale Centre-Ville

Montréal (Québec) H3C 3J7

Canada

http://www.sceco.umontreal.ca

SCECO-information@UMontreal.CA

Téléphone : (514) 343-6539

Télécopieur : (514) 343-7221

Ce cahier a également été publié par le Centre interuniversitaire de recherche en économie quantitative (CIREQ) sous le numéro 3397.

This working paper was also published by the Center for Interuniversity Research in Quantitative Economics (CIREQ), under number 3397.

ISSN 0709-9231 


\title{
CAHIER 9816
}

\section{SAMPLING INTERVAL AND ESTIMATED BETAS : IMPLICATIONS FOR THE PRESENCE OF TRANSITORY COMPONENTS IN STOCK PRICES}

\author{
Pierre PERRON ${ }^{1}$ and Cosme VODOUNOU ${ }^{2}$
}

\begin{abstract}
1 Centre de recherche et développement en économique (C.R.D.E.) and Département de sciences économiques, Université de Montréal, and Department of Economics, Boston University

2 Institut National de la Statistique et de l'Analyse Économique, Bénin
\end{abstract}

December 1997

This paper is drawn from chapter 3 of Vodounou's Ph.D. Dissertation at the Université de Montréal [Vodounou (1997)]. Perron acknowledges financial support from the Social Sciences and Humanities Research Council (SSHRC) of Canada, the Natural Sciences and Engineering Research Council (NSERC) of Canada, and the Fonds pour la Formation de chercheurs et l'aide à la recherche (FCAR) of Québec. 


\section{RÉSUMÉ}

Nous donnons un cadre théorique pour expliquer le fait empirique que les bêta estimés sont sensibles à l'intervalle de l'échantillon même en utilisant des rendements composés sans interruption. La composante permanente est un mouvement brownien géométrique standard et la composante transitoire est un processus stationnaire OrsteinUhlenbeck. La représentation en temps discret des bêta dépend de l'intervalle de l'échantillon et de deux composantes appelées "bêta permanent et transitoire". Nous montrons que, si la composante transitoire n'est pas présente dans les prix des actifs, il n'existe pas d'effet d'intervalle de l'échantillon. Cependant, la présence d'une composante transitoire implique que le bêta est une fonction croissante (décroissante) de l'intervalle de l'échantillon pour actifs plus (moins) risqués. Dans notre cadre théorique, les actifs sont risqués si ses "bêta permanents" sont plus grands que ses "bêta transitoires" et vice versa pour des actifs moins risqués. Les simulations montrent que nos résultats théoriques donnent une bonne approximation pour les moyennes et écart-types des bêta estimés en petits échantillons. Nos résultats peuvent être perçus comme une évidence indirecte de la présence d'une composante transitoire dans les prix des actifs, comme proposé par Fama et French (1988) et Poterba et Summers (1988).

Mots clés : équations différentielles stochastiques, processus de Wiener, efficacité des marchés, retour à la moyenne, processus d'Ornstein-Uhlenbeck

\section{ABSTRACT}

We provide a theoretical framework to explain the empirical finding that the estimated betas are sensitive to the sampling interval even when using continuously compounded returns. We suppose that stock prices have both permanent and transitory components. The permanent component is a standard geometric Brownian motion while the transitory component is a stationary Ornstein-Uhlenbeck process. The discrete time representation of the beta depends on the sampling interval and two components labelled "permanent and transitory betas". We show that if no transitory component is present in stock prices, then no sampling interval effect occurs. However, the presence of a transitory component implies that the beta is an increasing (decreasing) function of the sampling interval for more (less) risky assets. In our framework, assets are labelled risky if their "permanent beta" is greater than their "transitory beta" and vice versa for less risky assets. Simulations show that our theoretical results provide good approximations for the means and standard deviations of estimated betas in small samples. Our results can be perceived as indirect evidence for the presence of a transitory component in stock prices, as proposed by Fama and French (1988) and Poterba and Summers (1988).

Key words : stochastic differential equations, Wiener process, market efficiency, meanreversion, Ornstein-Uhlenbeck process 


\section{Introduction}

The Capital Asset Pricing Model (CAPM) has been the object of numerous studies over the past thirty years. Developed by Sharpe (1964) and Lintner (1965), it is based on the assumption that investors are risk-averse and construct their portfolios according to a meanvariance criterion. The basic relation says that in equilibrium there exists a linear relation between the return of a given asset or portfolio and the return of the market portfolio.

An empirical feature that has attracted some attention is the fact that the estimated beta (or systematic risk of an asset or portfolio) is sensitive to the sampling interval used to compute the returns. This "interval effect" has been analyzed in relation with another anomaly, the size effect, which shows a significant relation between returns and the market values of firms. Banz (1981) has analyzed this effect and showed that the smaller is a firm the higher is its expected return. For the interval effect, the empirical studies show that changes in the sampling interval used induce a bias in the estimate of the systematic risk whose magnitude depend on the size of the firms as measured by their market value.

According to Pogue and Solnik (1974), Roll (1981) and Reinganum (1982), the beta is under-estimated for small firms and overestimated for large firms when using daily data. Such a bias is attributed to the small frequency at which the assets of small firms are transacted [Scholes and Williams (1977) and Dimson (1979)] and more generally to frictions in the exchange process [Cohen, Hawawini, Maier, Schwartz and Whitcomb (1983)]. According to Cohen et al., prices adjust following the arrival of information and the adjustment delays are related to the size of firms. Accordingly, for large firms with a greater trading volume, the adjustment delays are shorter than for small firms whose trading volume is smaller. The infrequent exchange for small firms is accompanied with the non-synchronization of individual prices in relation to the market index which induces an intertemporal correlation between returns and an autocorrelation in the market returns.

In this study, we shall not be concerned about such relations holding at very short sampling interval where market microstructure effect are operative. Rather, we shall concentrate on ranges of sampling interval where these market microstructure effects are not present; for example constructing returns from weekly to annual intervals. On a theoretical level, Levary and Levy (1977) and Hawawini (1980) show a relation between the beta and the sampling interval in the case where the returns are computed using the relative prices $P(t h) / P((t-1) h)$

to define the $h$-periods returns. In such cases, the "interval effect" is simply due to an accounting issue. 
With relative prices used to construct returns Handa, Kothari and Wasley $(1989,1993)$ show clearly that an interval effect is present empirically and that the betas of more risky assets increase as the sampling interval increases, while the betas of less risky assets are decreasing. Their results also show that the estimated betas approach that of the market portfolio (i.e. one) when the sampling interval gets smaller. They argue that if continuously compounded returns (the first difference of the $\log$ of prices) are used, no such interval effect should hold if the market is efficient. An interesting fact is that Corhay (1990) and Defrère (1995) show that similar sampling interval effect are present empirically when using continuously compounded returns.

The purpose of our study is to provide a theoretical framework where interval effects are present even when using continuously compounded returns. We suppose that stock prices have both permanent and transitory components. The permanent component is a standard geometric Brownian motion with constant volatility while the transitory component is a stationary Ornstein-Uhlenbeck process. We derive the discrete time representation of the beta which depends on the sampling interval and two components labelled "permanent and transitory betas" (to be defined explicitly). We show that if no transitory component is present in stock prices then no sampling interval effect occurs. However, the presence of a transitory component implies that the beta is an increasing (decreasing) function of the sampling interval for more risky (less risky) assets. In our framework assets are labelled risky if their "permanent beta" is greater than their "transitory beta" and vice versa for less risky assets. Simulations show that our theoretical results provide good approximations for the means and standard deviations of estimated betas in small samples.

According to our results, the presence of a transitory component is the crucial element to explain the "interval effect", without it no such effect should be present. This transitory component is similar to that used by Fama and French (1988) and Poterba and Summers (1988) to explain the presence of negative serial correlation in returns at long horizons. Our theoretical results and the presence of the interval effect empirically can be perceived as indirect evidence for the presence of a transitory component in stock prices as proposed by Fama and French (1988) and Poterba and Summers (1988).

The paper is structured as follows. Section 2 defines the basic model in continuous time and derives its discrete time representation. In section 3 , we discuss the properties of the beta in relation to the sampling interval and the limiting behavior of estimates of it. Section 4 provides simulation evidence that supports the theoretical results. Section 5 offers concluding comments and a mathematical appendix some technical derivations. 


\section{The Basic Model}

We denote by $P_{1}(t)$, the price of a stock or a portfolio at date $t$, and by $P_{2}(t)$ the price of the market portfolio at the same date. We suppose that each price has two multiplicative components. One, denoted $P_{i}^{a}(t)$ represents the transitory component while the other, denoted $P_{i}^{b}(t)$, is the permanent component. Hence, we have:

$$
P_{i}(t)=P_{i}^{a}(t) P_{i}^{b}(t) \quad(i=1,2)
$$

The assumption of a permanent and transitory component for stock prices is frequently made (see, e.g., Poterba and Summers (1988), and Fama and French (1988)). It is usually motivated by the fact that it allows negative correlation in returns over long horizons which has been shown to be present empirically. Also, we denote by lower cases, the logarithm of the respective components, i.e.:

$$
p_{i}^{j}(t)=\ln P_{i}^{j}(t) \quad(i=1,2 ; \quad j=a, b) .
$$

The continuous time model describing the time paths of each component is intentionally kept simple to highlight the features of interest and is not intended as a precise description of the behavior of stock prices at all sampling intervals. It is intended to be a useful approximation for the sampling intervals of interest, namely weekly to yearly, for which positive serial correlation due to market microstructure effects do not hold but for which negative serial correlation is a possibility in the presence of transitory components. Accordingly, the transitory $P_{i}^{a}(t)$ and permanent $P_{i}^{b}(t)$ components are governed by the following stochastic differential equations, defined over $[0, N]$, with $N$ the span of the data:

$$
\begin{aligned}
d p_{i}^{a}(t) & =-\gamma_{i} p_{i}^{a}(t) d t+\sigma_{i}^{a} d W_{i}^{a}(t), \\
d P_{i}^{b}(t) & =\alpha_{i} P_{i}^{b}(t) d t+\sigma_{i}^{b} P_{i}^{b}(t) d W_{i}^{b}(t),
\end{aligned}
$$

for $i=1,2$, with $W^{j}(t)=\left(W_{1}^{j}(t), W_{2}^{j}(t)\right)^{\prime},(j=a, b)$ where $W^{a}(t)$ and $W^{b}(t)$ are independent standard Weiner processes. We make the following assumptions:

$$
\begin{aligned}
& E W_{1}^{j}(t) W_{2}^{j}(t)=\rho_{j}, \quad 0 \leq\left|\rho_{j}\right| \leq 1, \quad j=a, b ; \\
& \gamma_{i}>0, \alpha_{i}>0, \quad \sigma_{i}^{a}>0, \sigma_{i}^{b}>0, \quad i=1,2 .
\end{aligned}
$$

The stochastic differential equation describing the dynamics of the transitory component specifies that the logarithm of the transitory component of prices $P_{i}^{a}(t)$ is an OrnsteinUhlenbeck process. Accordingly, the long term effect of a chock on the level of the transitory 
component is zero and constraining the parameters $\gamma_{i}(i=1,2)$ to be positive ensures mean reversion. On the other hand, the dynamics of the permanent component $P_{i}^{b}(t)$ is governed by a geometric Brownian motion. The parameters $\alpha_{i}$ here reflects mean returns. The parameters $\left(\sigma_{i}^{j}\right)^{2}(i=1,2$ and $j=a, b)$ represent the variances of the noise components $W_{i}^{j}(t)$ and are often called diffusion components. The parameters $\rho_{j}$ account for the correlation between the noise of the temporary components $(j=a)$ or permanent components $(j=b)$ of the price of the asset (or portfolio) and the price of the market portfolio. Such specifications are often encountered in the finance literature. For example, a geometric Brownian motion is often postulated for risky stock prices while an Ornstein-Uhlenbeck is used for riskless assets (e.g., the short term interest rate on a safe asset); see, e.g., Merton(1973) and Black and Scholes (1973).

The assumption of the independence of the Weiner processes $W^{a}(t)$ and $W^{b}(t)$, allows us to write the system (1) as two sub-systems; namely

$$
d p_{i}^{a}(t)=-\gamma_{i} p_{i}^{a}(t) d t+\sigma_{i}^{a} d W_{i}^{a}(t)
$$

and

$$
d P_{i}^{b}(t)=\alpha_{i} P_{i}^{b}(t) d t+\sigma_{i}^{b} P_{i}^{b}(t) d W_{i}^{b}(t)
$$

for $i=1,2$. The systems (2) and (3) have the following solutions:

$$
p_{i}^{a}(t)=p_{i}^{a}(0) \exp \left(-\gamma_{i} t\right)+\sigma_{i}^{a} \int_{0}^{t} \exp \left(-\gamma_{i}(t-s)\right) d W_{i}^{a}(s)
$$

and

$$
p_{i}^{b}(t)=p_{i}^{b}(0)+\left(\alpha_{i}-\frac{\left(\sigma_{i}^{b}\right)^{2}}{2}\right) t+\sigma_{i}^{b} W_{i}^{b}(t),
$$

for $i=1,2$ (see, e.g. Theorems 8.2.2 and 8.4.3 of Arnold (1974)). These solutions show that the logarithm of the transitory component is stationary while the logarithm of the permanent component is an integrated component with a linear trend. For simplicity and without loss of generality, we suppose, in what follows, that $p_{i}^{j}(0)=0(i=1,2 ; j=a, b)$.

To compare our model with that of Poterba and Summers (1988) and Fama and French (1988), we need to derive the discrete time representation. To that effect, we define the sampling interval $h$ such that $T h=N$ with $T$ the number of observations and $N$ the span of the data. We have the following discrete time solutions for (4) and (5).

Proposition 1 Let $p_{i}^{a}(t)$ and $P_{i}^{b}(t) \quad(i=1,2)$ be defined by (1), then the discrete time solutions for a sampling interval $h$ are given by:

$$
p_{i}^{a}(t h)=\exp \left(-\gamma_{i} h\right) p_{i}^{a}((t-1) h)+u_{i}(t h)
$$


and

$$
p_{i}^{b}(t h)-p_{i}^{b}((t-1) h)=\left(\alpha_{i}-\frac{\left(\sigma_{i}^{b}\right)^{2}}{2}\right) h+v_{i}(t h),
$$

for $i=1,2$ and $t=1, \ldots, T$; with

$$
u_{i}(t h)=\sigma_{i}^{a} \int_{(t-1) h}^{t h} \exp \left(-\gamma_{i}(t h-s)\right) d W_{i}^{a}(s),
$$

and

$$
v_{i}(t h)=\sigma_{i}^{b}\left(W_{i}^{b}(t h)-W_{i}^{b}((t-1) h)\right) .
$$

The proof follows immediately from the solutions (4) and (5). The errors $u_{i}(t h)$ and $v_{i}(t h)$ have mean zero, are independent and are identically normally distributed. The moments of order two satisfy (for $i=1,2$ ):

$$
\begin{aligned}
E\left[u_{i}^{2}(t h)\right] & =\frac{1-\exp \left(-2 \gamma_{i} h\right)}{2 \gamma_{i}}\left(\sigma_{i}^{a}\right)^{2}, \\
E\left[u_{1}(t h) u_{2}(t h)\right] & =\frac{1-\exp \left(-\left(\gamma_{1}+\gamma_{2}\right) h\right)}{\left(\gamma_{1}+\gamma_{2}\right)} \rho_{a} \sigma_{1}^{a} \sigma_{2}^{a}, \\
E\left[v_{i}^{2}(t h)\right] & =\left(\sigma_{i}^{b}\right)^{2} h, \\
E\left[v_{1}(t h) v_{2}(t h)\right] & =\rho_{b} \sigma_{1}^{b} \sigma_{2}^{b} h .
\end{aligned}
$$

We now need to define the returns over an horizon of $h$ periods. Supposing that dividends are zero (or that they are re-invested), the instantaneous returns are $R(t)=d \ln P(t) / d t$. Given the nature of the continuous-time solutions for prices as functions of Weiner processes, we cannot define the instantaneous ret urns (since the Weiner processes are non-differentiable). Nevertheless, we can use the discrete time solutions of prices to define the discrete time solution for returns over $h$ periods defined by:

$$
R_{i}(t h)=(1-L)\left(p_{i}^{a}(t h)+p_{i}^{b}(t h)\right),
$$

where $L$ is the lag operator such that $L x_{t}=x_{t-1}$. A representation for $R_{i}(t h)$ in terms of the errors $v_{i}(t h)$ and $u_{i}(t h)$ is given by:

$$
R_{i}(t h)=\left(\alpha_{i}-\frac{\left(\sigma_{i}^{b}\right)^{2}}{2}\right) h+v_{i}(t h)+\left(1-\exp \left(-\gamma_{i} h\right) L\right)^{-1}(1-L) u_{i}(t h) .
$$


Using the notation $R_{t h}=\left(R_{1}(t h), R_{2}(t h)\right)^{\prime}$, we can write

$$
R_{t h}=\Psi h+\eta_{t h}
$$

where $\Psi=\left(\Psi_{1}, \Psi_{2}\right)^{\prime}, \eta_{t h}=\left(\eta_{1}(t h), \eta_{2}(t h)\right)^{\prime}, \Psi_{i}=\alpha_{i}-\left(\sigma_{i}^{b}\right)^{2} / 2$ and

$$
\eta_{i}(t h)=v_{i}(t h)+\left(1-\exp \left(-\gamma_{i} h\right) L\right)^{-1}(1-L) u_{i}(t h)
$$

We can use these specifications to derive the following result pertaining to the discrete time representation of returns.

Proposition 2 In discrete time the returns $R_{i}($ th) are characterized by an $A R M A(1,1)$ process with first-order correlation coefficient given by:

$$
\operatorname{cov}\left(R_{i}(t h), R_{i}((t-1) h)\right)=-\frac{\left(1-\exp \left(-\gamma_{i} h\right)\right)^{2}}{2 \gamma_{i}}\left(\sigma_{i}^{a}\right)^{2}, \quad i=1,2 .
$$

In particular, for small $\gamma_{i}$ or $h$ we have the approximation:

$$
\operatorname{cov}\left(R_{i}(t h), R_{i}((t-1) h)\right) \approx-\frac{\gamma_{i} h^{2}}{2}\left(\sigma_{i}^{a}\right)^{2}, \quad i=1,2,
$$

so that when either $\gamma_{i}$ or $h$ approaches 0 , the returns $R_{i}($ th $)$ are i.i.d..

This proposition shows that our model satisfies the same qualitative properties as that of Poterba and Summers (1988). In particular, it implies negative correlation in returns that becomes stronger as the horizon $h$ increases but that this correlation is negligeable for short horizons. Also, when the transitory component is nul $\left(\sigma_{i}^{a}=0\right.$ or $\left.\gamma_{i}=0\right)$ this correlation disappears and the returns are i.i.d..

In this study, we wish to consider the behavior of the estimator of the systematic risk (the betas) when the sampling interval is allowed to vary. To that effect, we shall adopt different asymptotic frameworks whereby either $h$ decreases to 0 keeping the span $N$ fixed, or keeping $h$ fixed and letting the span $N$ increases.

\section{Estimates of beta: asymptotic properties and implications}

We start by defining the notion of the systematic risk beta implied by the model and it's limit value as the sampling interval increases or decreases. After a discussion of the population value, we turn to the characterization of the estimates. 


\subsection{Population values of betas.}

Definition 1 Let $R_{t h}=\left(R_{1}(t h), R_{2}(t h)\right)^{\prime}$ be defined by (9). For a sampling interval $h$, the systematic risk is defined by:

$$
\beta_{0 h}=\frac{\operatorname{cov}\left(R_{1}(t h), R_{2}(t h)\right)}{\operatorname{var}\left(R_{2}(t h)\right)}
$$

In particular, if $h \rightarrow 0$, we use the notation $\beta_{\mathbf{0}}=\lim _{h \rightarrow \mathbf{0}} \beta_{\mathbf{0} h}$ and if $h \rightarrow \infty$, we use $\tilde{\beta}_{0 b}=\lim _{h \rightarrow \infty} \beta_{0 h}$.

We have the following representation of $\beta_{0 h}$ as a function of the sampling interval $h$ and the parameters of the model.

Proposition 3 Let $R_{t h}=\left(R_{1}(t h), R_{2}(t h)\right)^{\prime}$ be defined by (9) and $\beta_{0 h}$ by (1D). We have:

$$
\beta_{0 h}=\frac{\rho_{b} \sigma_{1}^{b} \sigma_{2}^{b}+\rho_{a} \sigma_{1}^{a} \sigma_{2}^{a} \frac{2-\exp \left(-\gamma_{1} h\right)-\exp \left(-\gamma_{2} h\right)}{\left(\gamma_{1}+\gamma_{2}\right) h}}{\left(\sigma_{2}^{b}\right)^{2}+\left(\sigma_{2}^{a}\right)^{2} \frac{1-\exp \left(-\gamma_{2} h\right)}{\gamma_{2} h}} .
$$

If $h \rightarrow 0$, we have:

$$
\beta_{0}=\frac{\rho_{b} \sigma_{1}^{b} \sigma_{2}^{b}+\rho_{a} \sigma_{1}^{a} \sigma_{2}^{a}}{\left(\sigma_{2}^{b}\right)^{2}+\left(\sigma_{2}^{a}\right)^{2}}
$$

and if $h \rightarrow \infty$,

$$
\widetilde{\beta}_{0 b}=\frac{\rho_{b} \sigma_{1}^{b}}{\sigma_{2}^{b}}
$$

The expression (13) differ from those of Levary and Levy (1977) and Hawawini (1980) who present the ratio of an asset's beta computed over $h$ periods relative to that over one period as a function of $h$ and intertemporal cross correlations. The relation (13) suggests that if the transitory component is not present in the assets' prices $\left(\sigma_{1}^{a}=\sigma_{2}^{a}=0\right)$, the

true value of beta is independent of the sampling interval and coincides with $\widetilde{\beta}_{0 b}$ defined as the limit of $\beta_{0 h}$ when $h$ increases. Hence, without the transitory component the sampling: interval does not affect the value of the beta. For that reason, we shall refer to $\widetilde{\beta}_{\mathbf{0} b}$ as the "permanent-beta". By analogy, we refer to $\widetilde{\beta}_{0 a}=\rho_{a} \sigma_{1}^{a} / \sigma_{2}^{a}$ as the "transitory-beta". It is the value that the beta would take in the absence of a permanent component when $h$ is small. Using this notation, we see that the true value of beta, $\beta_{0 h}$, is a function of $\widetilde{\beta}_{0 b}, \widetilde{\beta}_{0 a}$ and $h$ given by:

$$
\beta_{0 h}=\frac{\tilde{\beta}_{0 b}+\widetilde{\beta}_{0 a}\left(\sigma_{2}^{a} / \sigma_{2}^{b}\right)^{2} \frac{2-\exp \left(-\gamma_{1} h\right)-\exp \left(-\gamma_{2} h\right)}{\left(\gamma_{1}+\gamma_{2}\right) h}}{1+\left(\sigma_{2}^{a} / \sigma_{2}^{b}\right)^{2} \frac{1-\exp \left(-\gamma_{2} h\right)}{\gamma_{2} h}} .
$$


For small values of the sampling interval $h$, we have

$$
\beta_{\mathbf{0}}=\frac{\left(\sigma_{2}^{b}\right)^{2} \widetilde{\beta}_{0 b}+\left(\sigma_{2}^{a}\right)^{2} \widetilde{\beta}_{0 a}}{\left(\sigma_{2}^{b}\right)^{2}+\left(\sigma_{2}^{a}\right)^{2}}
$$

which shows that the beta is a linear combination of the permanent and transitory betas. The equation (16) also makes clear that, when the permanent and transitory betas are equal, they both correspond to $\beta_{0}$ and, hence, there is no interval effect since the beta is the same for small and large values of the sampling interval $h$.

Figure 1.0 presents the graph of $\beta_{0 h}$ as a function of $h$. It shows that if $\widetilde{\beta}_{0 a}<\widetilde{\beta}_{0 b}$ (resp. $\tilde{\beta}_{0 a}>\widetilde{\beta}_{0 b}$ ) then $\beta_{0 h}$ is a strictly increasing (resp. decreasing) function of $h$ for any $\gamma_{i}>0$.

However, when $\widetilde{\beta}_{0 a}=\widetilde{\beta}_{0 b}$, the true value $\beta_{0 h}$ is independent of $h$ if $\gamma_{1}=\gamma_{2}$ and is a nonmonotonic function of $h$ if $\gamma_{1} \neq \gamma_{2}$. Note that if $\gamma_{i}$ is very small, $\beta_{0 h}=\beta_{0}$ and there is no sampling interval effect.

\subsection{Properties of estimates of betas}

We now turn to the properties of estimates of $\beta_{h}$. To that effect, we define the following Capital Asset Pricing Model (CAPM) for any given sampling interval $h$

$$
R_{1}(t h)=\alpha_{0 h}+\beta_{0 h} R_{2}(t h)+e(t h),
$$

with

$$
\alpha_{0 h}=\left(\alpha_{1}-\frac{\left(\sigma_{1}^{b}\right)^{2}}{2}\right) h^{1 / 2}-\beta_{0 h}\left(\alpha_{2}-\frac{\left(\sigma_{2}^{b}\right)^{2}}{2}\right) h^{1 / 2},
$$

and

$$
e(t h)=\eta_{1}(t h)-\beta_{0 h} \eta_{2}(t h) .
$$

The ordinary least-squares estimate of $\beta_{h}$ is:

$$
\hat{\beta}_{h}=\frac{\sum_{t=1}^{T}\left(R_{1}(t h)-\bar{R}_{1}\right)\left(R_{2}(t h)-\bar{R}_{2}\right)}{\sum_{t=1}^{T}\left(R_{2}(t h)-\bar{R}_{2}\right)^{2}},
$$

where $\bar{R}_{i}=T^{-1} \sum_{t=1}^{T} R_{i}(t h)$ for $i=1,2$.

Proposition 4 For any sampling interval $h$, we have, as $T \rightarrow \infty$ :

$$
T^{1 / 2}\left(\widehat{\beta}_{h}-\beta_{0 h}\right) \rightarrow^{d} N\left(0, V_{h}\right)
$$


with

$$
\begin{aligned}
V_{h} & \equiv \lim _{T \rightarrow \infty} \operatorname{Tvar}\left(\hat{\beta}_{h}-\beta_{0 h}\right) \\
& =\frac{\left(\sigma_{1}^{a}\right)^{2} \frac{1-\exp \left(-\gamma_{1} h\right)}{\gamma_{1} h}+\left(\sigma_{1}^{b}\right)^{2}-\beta_{0 h}^{2}\left[\left(\sigma_{2}^{a}\right)^{2} \frac{1-\exp \left(-\gamma_{2} h\right)}{\gamma_{2} h}+\left(\sigma_{2}^{b}\right)^{2}\right]}{\left(\sigma_{2}^{b}\right)^{2}+\left(\sigma_{2}^{a}\right)^{2} \frac{1-\exp \left(-\gamma_{2} h\right)}{\gamma_{2} h}} .
\end{aligned}
$$

If $h \rightarrow 0$, we have:

$$
V_{\mathbf{0}} \equiv \lim _{h \rightarrow \mathbf{0}} V_{h}=\frac{\left(\sigma_{1}^{b}\right)^{2}+\left(\sigma_{1}^{a}\right)^{2}-\beta_{\mathbf{0}}^{2}\left[\left(\sigma_{2}^{b}\right)^{2}+\left(\sigma_{2}^{a}\right)^{2}\right]}{\left(\sigma_{2}^{b}\right)^{2}+\left(\sigma_{2}^{a}\right)^{2}}
$$

and if $h \rightarrow \infty$,

$$
V_{\infty} \equiv \lim _{h \rightarrow \infty} V_{h}=\widetilde{\beta}_{\mathbf{0} b}^{2}\left(1-\rho_{b}^{2}\right) / \rho_{b}^{2},
$$

which corresponds to the asymptotic variance for any fixed $h$ in the absence of a transitory component.

The proof of this result is quite standard and omitted. What it basically says is that the estimated betas will be close to the true betas as defined by $\beta_{0 h}$. Hence, we can approximate the behavior of the estimated betas by the behavior of the population values as $h$ varies. Of interest also, is the fact that when $h$ is large, the variance of the estimated beta is directly proportional to the permanent beta. This last convergence result for $\hat{\beta}_{h}$ in conjunction with Proposition 3 concerning the behavior of $\beta_{\mathbf{0} h}$ as a function of $h$ have the following: implications:

- In the absence of a transitory component in prices, there is no sampling interval effect on the estimated betas, for large enough sample sizes;

- If the transitory and permanent betas are equal there will, to a first approximation, also be no sampling interval effect;

- With a transitory component in prices and a difference between the permanent and transitory betas, the limit of $\hat{\beta}_{h}$ when $h$ increases (which corresponds to the permanent beta) can be less than or greater than $\beta_{\mathbf{0}}$ (the limit as $h$ goes to zero) which is a linear combination of the permanent and transitory beta. The sign of the difference will depend on the sign of the difference between the permanent and transitory beta. 
We can explain the systematic bias $\left(E \hat{\beta}_{h}-\beta_{\mathbf{0}}\right)$ in terms of some relations which have a direct link with the size of a firm. To make explicit these relations, we first define some concepts.

Definition 2 We say that there is under-evaluation of the beta when $\widetilde{\beta}_{0 b}<\beta_{0}$ or equivalently when the limit of $\hat{\beta}_{h}$ when $h$ increases is less than the limit of $\hat{\beta}_{h}$ when $h$ decreases. Conversely, we say that there is over-evaluation when $\widetilde{\beta}_{0 b}>\beta_{\mathbf{0}}$.

These definitions only involve the limiting values $\beta_{\mathbf{0}}$ et $\widetilde{\beta}_{\mathbf{0} b}$. Intuitively, the sampling: interval $h$ can be interpreted for an investor as the horizon of the investments' profitability (Levary and Levy (1977)). Under the hypothesis that the investors often choose a short horizon for such purposes, the beta corresponding to the "true horizon" would be $\beta_{0}$. In general, $\beta_{0}$ is a linear combination of the permanent and transitory betas. If these are equal, then the beta at a short horizon $\left(\beta_{0}\right)$ is the same as the beta at a long horizon $\left(\tilde{\beta}_{0 b}\right)$ and increases in the sampling interval involves no biases. Consider now the case where the transitory beta is smaller than the permanent one $\left(\widetilde{\beta}_{\mathbf{0} a}<\widetilde{\beta}_{\mathbf{0} b}\right)$. This implies that the systematic risk is larger for the long term than over the short term. This is the characteristic of more risky firms in the sense that short term considerations do not account for all of the risk. Hence, following Banz (1981), we may interpret this case as applying to small firms. Thus, for small firms, the limit of $\hat{\beta}_{h}$ increases if the sampling interval increases and there is over-evaluation of the betas (this follows since, if $\widetilde{\beta}_{\mathbf{0} b}>\widetilde{\beta}_{\mathbf{0} a}$, we have, taking the limit as $\left.h \rightarrow 0, \widetilde{\beta}_{0 b}>\beta_{h}>\beta_{0}>\widetilde{\beta}_{0 a}\right)$. The case with the permanent beta smaller than the transitory beta is one where short term considerations account for more of the long term risk. We may thus expect this case to apply to less risky or larger firms. Thus for large firms, we have he opposite relation, namely $\hat{\beta}_{h}$ decreases with an increase in the sampling interval and there is under-evaluation of the betas.

\section{Simulation Experiments}

In this section, we verify if the theoretical results obtained provide an adequate description of the finite sample properties of the estimates of the betas and if these are robust to various changes in the parameters. As interesting cases for the simulations, we consider the 3 cases depicted in Figure 1, namely:

- Case 1: $\widetilde{\beta}_{\mathbf{0} b}=\widetilde{\beta}_{\mathbf{0} a}$. If the permanent and transitory betas are identical, then the limit of $\hat{\beta}_{h}$ is independent of $h$ when the coefficients $\gamma_{i}$ (which control the degree of mean- 
reversion) are equal $\left(\gamma_{1}=\gamma_{2}\right)$. However, if $\gamma_{1} \neq \gamma_{2}$, the limit of $\hat{\beta}_{h}$ is a non-monotonic function of $h$.

- Case 2: $\widetilde{\beta}_{0 b}<\widetilde{\beta}_{0 a}$. If the permanent beta is less than the transitory beta, the limit of $\hat{\beta}_{h}$ decreases if the sampling interval increases and there is under-evaluation of the betas.

- Case 3: $\widetilde{\beta}_{0 b}>\widetilde{\beta}_{0 a}$. If the permanent beta is greater than the transitory beta, $\hat{\beta}_{h}$ increases with an increase in the sampling interval and there is over-evaluation of the betas.

The cases 2 and 3 are consistent with the theoretical results of Levary and Levy (1977) and of Handa and al. (1989) concerning the monotonicity result that the betas of risky assets increase with the sampling interval, while the betas of less risky assets decrease with the sampling interval.

\subsection{Calibration of the model}

To calibrate the model, we first start by normalizing $\beta_{\mathbf{0}}$ to 1 . This leads us to retain values of $\tilde{\beta}_{0 a}=\rho_{a} \sigma_{1}^{a} / \sigma_{2}^{a}$ and $\widetilde{\beta}_{0 b}=\rho_{b} \sigma_{1}^{b} / \sigma_{2}^{b}$ which satisfy for case 2 the inequality $\widetilde{\beta}_{0 b}<1<\widetilde{\beta}_{0 a}$, and for case 3 , the inequality $\widetilde{\beta}_{0 a}<1<\widetilde{\beta}_{0 b}$. For case 1 , we have the equality $\widetilde{\beta}_{0 b}=\widetilde{\beta}_{0 a}=1$ when $\gamma_{1}=\gamma_{2}$. We select the values of $\rho_{a}, \sigma_{1}^{a}, \sigma_{2}^{a}, \rho_{b}, \sigma_{1}^{b}$, and $\sigma_{2}^{b}$ to have five base cases, see Table 1. The first, $P 1$, specifies that the asset or portfolio have a permanent and a transitory beta which are equal $\widetilde{\beta}_{0 b}=\widetilde{\beta}_{0 a}=1$. For the second portfolio, $P 2$, the permanent beta is much less than the tansitory beta $\left(\widetilde{\beta}_{0 b}=0.15\right.$ and $\left.\widetilde{\beta}_{0 a}=1.35\right)$. For the third portfolio, the difference between the transitory and permanent betas is reduced $\left(\widetilde{\beta}_{\mathbf{0} b}=0.90\right.$ and $\left.\widetilde{\beta}_{\mathbf{0} a}=1.35\right)$. For portfolios 4 and 5 , the specifications are the same as for portfolios 2 and 3 except that we interchange the values for $\widetilde{\beta}_{0 a}$ and $\widetilde{\beta}_{0 b}$.

The values retained for the coefficients $\gamma_{i}$ are $0.20,0.60$ and 0.01 . The value 0.01 is considered to illustrate the effect of a weak reversion to the mean for the transitory component. Here, we can no longer really consider that component as transitory since it is nearly integrated, and we would expect to have results corresponding to the no-transitory component case. The other values are such that they imply autoregressive coefficients of 0.98 and 0.95 selected by Poterba and Summers (1988) with monthly data $(-0.20 \simeq 12 \ln (0.98)$ and $-0.6 \simeq 12 \ln (0.95)$ ). Given the absence of any empirical results giving information on the relative magnitude of $\gamma_{1}$ (the mean-reversion coefficient for a stock or portfolio) and $\gamma_{2}$ 
(the mean-reversion coefficient for the market portfolio), we set $\gamma_{1}=\gamma_{2}$ in the base case. However, given that returns are $\operatorname{ARMA}(1,1)$ stationary processes for any fixed $h$, it is likely that the effect of a shock on the transitory component of prices becomes negligeable faster than for the market portfolio for some types of assets and slower for others. Hence, we also assess the extent to which the results are sensitive to setting $\gamma_{2} / \gamma_{1}<1$ or $\gamma_{2} / \gamma_{1}>1$.

\subsection{Specifications of the simulation design}

To assess the effect of the sampling interval on the distribution of $\hat{\beta}_{h}$, the number of observations $T$ and the sampling interval $h$ are chosen such that $T=25,50,100$, and 200 and $h=0,1,2,4,8,12,24$, and $\infty$. For a given sampling interval $h$, we simulate $T$ independent realization of the processes $u^{*}(t h)=\left(u_{1}^{*}(t h), u_{2}^{*}(t h)\right)^{\prime}$ and $v^{*}(t h)=\left(v_{1}^{*}(t h), v_{2}^{*}(t h)\right)^{\prime}$ from a multivariate $N(0, \Omega)$ distribution where $\Omega$ is the variance-covariance matrix of the process $u^{*}(t h)$ or $v^{*}(t h)$ (see Proposition 1 ). We then construct the processes $\eta_{i}^{*}(t h)(i=1,2)$ and deduce from them the returns $R_{1}^{*}(t h)$ et $R_{2}^{*}(t h)$ and estimate $\beta_{h}$ from (18). We repeat this procedure 3000 times to obtain the distribution of the estimator.

\subsection{The finite sample distribution of $\hat{\beta}_{h}$ in the base case}

The results are presented in Tables 2, 3 and 4 for the cases $\gamma_{1}=\gamma_{2}=.20, \gamma_{1}=\gamma_{2}=.60$ and $\gamma_{1}=\gamma_{2}=.01$, respectively. In general, the results support the theoretical findings of section 3 .

If the transitory and permanent betas are equal $(P 1)$, there is indeed no sampling interval effect for any value of the mean-reversion coefficients $\gamma_{1}$ and $\gamma_{2}$. However, when the transitory beta is greater than the permanent beta, $\widetilde{\beta}_{0 a}>\widetilde{\beta}_{0 b}$, the mean of the estimated beta decreases as $h$ increases while the opposite holds when $\widetilde{\beta}_{0 a}<\widetilde{\beta}_{0 b}$. This rate of decrease (when $\widetilde{\beta}_{0 a}>$ $\widetilde{\beta}_{0 b}$ ) or increase (when $\widetilde{\beta}_{\mathbf{0} a}<\widetilde{\beta}_{\mathbf{0} b}$ ) is faster the larger is the difference between $\widetilde{\beta}_{\mathbf{0} a}$ and $\widetilde{\beta}_{\mathbf{0} b}$. The differences are also more important when the mean-reversion coefficient increases (i.e., from 0.2 to 0.6 ). When the mean-reversion coefficients are set to 0.01 , we see that the bias practically disappears. This is to be expected, since with such small value there is no longer a temporary component since it is almost integrated.

Consider now the standard deviations of the estimated betas presented in panels (b) of Tables 2 to 4 . We first remark that, among the cases considered, these are smallest for $P 1$ when the sampling interval effect is absent. They are also decreasing as $h$ increases unless $\gamma_{1}=\gamma_{2}=.01$. For the other portfolios, the behavior of the standard-deviations depends on the difference between the transitory and permanent betas. When this difference is 
large (portfolios $P 2$ and $P 4$ ), the betas of the risky portfolios $\left(\beta_{0 h}>1\right.$ ) are more precisely estimated than the betas of the less risky portfolios $\left(\beta_{0 h}<1\right)$. However, when the difference between the transitory and permanent betas is smaller (portfolios $P 3$ and $P 5$ ), the standard deviations are larger for more risky portfolios. For such portfolios ( $P 3$ and $P 5)$ we do not observe the same monotonic behavior for the standard deviations as $h$ increases as for the portfolios $P 2$ and $P 4$. When the difference between the transitory and permanent betas is large, the standard deviations decrease as $h$ increases; when the difference is smaller they tend to remain constant or increase as $h$ increases.

The fact that portfolios for which the estimated betas increase with $h\left(\beta_{0 h}>1\right)$ are less variable (smaller standard deviations of the estimated betas) contrasts with some empirical results which showed that volatility is in general larger for small firms and that it has a tendency to increase with the sampling interval; see Corhay (1990) and Handa et al. (1989).

Finally, it is important to remark that the bias in the estimated betas is almost entirely due to the systematic bias $\left(E \hat{\beta}_{h}-\beta_{0}\right)$ as opposed to the statistical bias $\left(E \hat{\beta}_{h}-\beta_{0 h}\right)$. Results, not reported, show the latter to be close to zero in all cases.

\subsection{Sensitivity Analyses}

To study the sensitivity of the results to changes in various parameters, we consider, as a basis for reference, the case where $\gamma_{1}=\gamma_{2}=0.20$ and the difference between $\widetilde{\beta}_{0 a}$ and $\widetilde{\beta}_{0 b}$ is large, for example $\widetilde{\beta}_{\mathbf{0} a}>\widetilde{\beta}_{\mathbf{0} b}$ with $\widetilde{\beta}_{\mathbf{0} a}=1.35$ and $\widetilde{\beta}_{\mathbf{0} b}=0.15$ (Table 2 with $P 2$ ). We performed simulations using different cases as a basis for reference and the conclusions are similar.

The sensitivity of the results is analyzed in three directions in relation to the sub-groups of parameters $\left(\gamma_{1}, \gamma_{2}\right),\left(\rho_{a}, \sigma_{1}^{a}, \sigma_{2}^{a}\right)$ and $\left(\rho_{b}, \sigma_{1}^{b}, \sigma_{2}^{b}\right)$. The strategy is to vary the parameters of one group while keeping the others constant. We first consider variations in the parameters $\left(\gamma_{1}, \gamma_{2}\right)$ and in particular on the effect of specifying $\gamma_{1}>\gamma_{2}$ or $\gamma_{1}<\gamma_{2}$. Secondly, we analyze the effect of changing the parameters of the variance-covariance matrix of the transitory

component keeping constant $\widetilde{\beta}_{0 a}=\rho_{a} \sigma_{1}^{a} / \sigma_{2}^{a}$. Finally, we examine the effect of changes in the parameters $\left(\rho_{b}, \sigma_{1}^{b}, \sigma_{2}^{b}\right)$, related to the permanent component, keeping constant $\widetilde{\beta}_{0 b}=$ $\rho_{b} \sigma_{1}^{b} / \sigma_{2}^{b}$.

\subsubsection{Effect of changes in the parameters $\gamma_{i}$}

Table 5 presents the mean of the estimated betas as a function of $h$ for different values of $\gamma_{1}$ (resp. $\gamma_{2}$ ) when $\gamma_{2}$ (resp. $\gamma_{1}$ ) is fixed, the reference curve corresponding to the case 
$\gamma_{1}=\gamma_{2}=0.20$. We observe that the monotonically decreasing behavior of the estimated betas is not affected by alternative choices of the mean-reversion parameters. However, changes in these parameters have an influence on the systematic $\left(E \hat{\beta}_{h}-\beta_{0}\right)$ and statistical $\left(E \hat{\beta}_{h}-\beta_{0 h}\right)$ biases in small samples $(T=25$ or 50$)$. Indeed, the systematic bias (measured as the distance between each curve and the horizontal line $\beta_{0}=1$ ) increases (in absolute value) as $\gamma_{1} / \gamma_{2}$ increases with $\gamma_{2}$ fixed or when $\gamma_{2} / \gamma_{1} \geq 1$ with $\gamma_{1}$ fixed.

Consider the statistical bias, which we approximate as the difference between the means at $T=25$ and $T=200$. From Table 5 , we see that it is positive (except for $h=4$ and 8 ). Its relative magnitude depends on the ratio $\gamma_{2} / \gamma_{1}$ but the pattern does not appear to be monotonic.

As shown in Table 5, changes in the mean-reversion coefficients affect the standard deviations of the estimated betas. It is smaller when $\gamma_{1} / \gamma_{2}>1$ and larger when $\gamma_{1} / \gamma_{2}<1$.

\subsubsection{Effect of changes in the parameters $\left(\rho_{a}, \sigma_{1}^{a}, \sigma_{2}^{a}\right)$ and $\left(\rho_{b}, \sigma_{1}^{b}, \sigma_{2}^{b}\right)$}

We analyze jointly the effect of changes in the parameters $\rho_{a}, \sigma_{1}^{a}$ and $\sigma_{2}^{a}$ (resp. $\rho_{b}, \sigma_{1}^{b}$ and $\sigma_{2}^{b}$ ) keeping $\widetilde{\beta}_{0 a}=\rho_{a} \sigma_{1}^{a} / \sigma_{2}^{a}\left(\operatorname{resp} \widetilde{\beta}_{0 b}=\rho_{b} \sigma_{1}^{b} / \sigma_{2}^{b}\right)$ and the ratio $\sigma_{2}^{a} / \sigma_{2}^{b}$ fixed (the reference values are those in Table 2 for the case $P 2$ ). From the results, presented in Table 6 , we see that the sampling interval effect remains and that changes in these parameters affects the systematic and statistical biases. The systematic bias is always negative (except for some rare cases) and its importance increases as $\sigma_{1}^{a}$ increases. For example, in Table 2 with $\sigma_{1}^{a}=3.01$, the systematic bias is -0.066 for $T=25$ and $h=2$ and -0.275 when $h=12$; on the other hand, from Table 6 , for the same value of $T$, it is -0.074 and -0.290 , for $h=2$ and 12 , respectively, when $\sigma_{1}^{a}=21.040$. The corresponding values are -0.048 and -0.273 when $\sigma_{1}^{a}=5.26$. A similar behavior is observed for the statistical bias for $T=25$ unlike the reference case which basically showed no such bias.

Concerning the parameters $\rho_{b}, \sigma_{1}^{b}$ and $\sigma_{2}^{b}$, Table 6 (compared to the reference case) shows that variations in these parameters do not significantly affect the mean and standard deviations of the estimated betas. However, if $\sigma_{2}^{b}$ is very large relative to $\sigma_{1}^{b}$, there can be large dispersions in small samples when $h$ is small.

\section{Conclusion}

In this study, we have provided a theoretical framework to analyze the empirically supported effect of the sampling interval used to compute returns on the estimated betas. The model 
used specifies the presence of both permanent and transitory components in prices as in Fama and French (1988) and Poterba and Summers (1988). As in these papers, the discretetime representation of returns is an $A R M A(1,1)$ process with negative serial correlation. We have derived the corresponding theoretical value of the beta not only as a function of the sampling interval but also of the various parameters of the permanent and transitory components.

Our theoretical results show the importance of the presence of a transitory components in explaining the effect of the sampling interval. Without such a component the betas and their estimates show no relation to the sampling interval. With it, there is a clear monotonic relation whose sign depends on the difference between what we call the permanent and transitory betas. We argues that small firms which are more risky have a transitory beta smaller than the permanent beta and that this implies a beta which increases as the sampling interval decreases. The inverse relation holds for large firms whose transitory beta is greater than the permanent beta. Our theoretical results which rely on asymptotic arguments are shown to yield adequate approximations in finite sample using simulation experiments. The extent to which the presence of a transitory component affects the strength of the sampling interval effect depends on parameters such as the coefficients of mean-reversion for the stock (or portfolio) and for the market portfolio.

What we have established is that, in our framework, it is possible to explain the empirical results of Handa et al. (1989), Corhay (1990) and Defrère (1995) only when a transitory component in present in prices. We interpret this as indirect evidence giving support to the claims made by Poterba and Summers (1988) and Fama and French (1988). 


\section{Mathematical Appendix}

Proof of Proposition 2: From the definition of $\eta_{i}(t h)$ as:

$$
\eta_{i}(t h)=v_{i}(t h)+\left(1-\exp \left(-\gamma_{i} h\right) L\right)^{-1}(1-L) u_{i}(t h),
$$

we can write, after some manipulations:

$$
\eta_{i}(t h)=v_{i}(t h)+u_{i}(t h)+\left(1-\frac{1}{\phi_{i}}\right) \sum_{j=1}^{\infty} \phi_{i}^{j} u_{i}((t-j) h),
$$

with $\phi_{i}=\exp \left(-\gamma_{i} h\right)$. Consider first the variance of $R_{i}(t h)$. We have:

$$
\begin{aligned}
\operatorname{var}\left(R_{i}(t h)\right) & =\sigma_{v_{i}}^{2}+\sigma_{u_{i}}^{2}+\left(1-\frac{1}{\phi_{i}}\right)^{2} \sigma_{u_{i}}^{2} \sum_{j=1}^{\infty} \phi_{i}^{2 j} \\
& =\sigma_{v_{i}}^{2}+\sigma_{u_{i}}^{2}+\sigma_{u_{i}}^{2}\left(1-\frac{1}{\phi_{i}}\right)^{2}\left(\frac{1}{1-\phi_{i}^{2}}-1\right) \\
& =\sigma_{v_{i}}^{2}+\frac{2}{1+\phi_{i}} \sigma_{u_{i}}^{2} .
\end{aligned}
$$

Substituting for $\phi, \sigma_{v_{i}}^{2}$ and $\sigma_{u_{i}}^{2}$, we obtain:

$$
\operatorname{var}\left(R_{i}(t h)\right)=\left(\sigma_{i}^{a}\right)^{2} \frac{1-\exp \left(-\gamma_{i} h\right)}{\gamma_{i}}+\left(\sigma_{i}^{b}\right)^{2} h .
$$

Consider now the covariance of $R_{i}(t h)$ and $R_{i}((t-1) h)$. We have:

$$
\begin{aligned}
\operatorname{cov}\left(R_{i}(t h), R_{i}((t-1) h)\right)= & \operatorname{cov}\left(\eta_{i}(t h), \eta_{i}((t-1) h)\right) \\
= & -\frac{1-\phi_{i}}{\phi_{i}} \operatorname{cov}\left(u_{i}((t-1) h), \sum_{j=1}^{\infty} \phi_{i}^{j} u_{i}((t-j) h)\right) \\
& +\left(\frac{1-\phi_{i}}{\phi_{i}}\right)^{2} \sum_{k=2}^{\infty} \phi_{i}^{k-1} \operatorname{cov}\left(u_{i}((t-k) h), \sum_{j=1}^{\infty} \phi_{i}^{j} u_{i}((t-j) h)\right) .
\end{aligned}
$$

Upon some developments, we obtain:

$$
\begin{aligned}
\operatorname{cov}\left(R_{i}(t h), R_{i}((t-1) h)\right) & =-\frac{1-\phi_{i}}{\phi_{i}} \phi_{i} \sigma_{u_{i}}^{2}+\frac{\left(1-\phi_{i}\right)^{2}}{\phi_{i}^{3}} \sigma_{u_{i}}^{2} \sum_{k=2}^{\infty} \phi_{i}^{2 k} \\
& =-\frac{1-\phi_{i}}{1+\phi_{i}} \sigma_{u_{i}}^{2} \\
& =-\frac{\left(1-\phi_{i}\right)^{2}}{2 \gamma_{i}}\left(\sigma_{i}^{a}\right)^{2} \\
& =-\frac{\left(1-\exp \left(-\gamma_{i} h\right)\right)^{2}}{2 \gamma_{i}}\left(\sigma_{i}^{a}\right)^{2} .
\end{aligned}
$$


We deduce that:

$$
\lim _{h \rightarrow \mathbf{0}} \operatorname{cov}\left(R_{i}(t h), R_{i}((t-1) h)\right)=0
$$

and

$$
\lim _{\gamma_{i} \rightarrow \mathbf{0}} \operatorname{cov}\left(R_{i}(t h), R_{i}((t-1) h)\right)=0 .
$$

Consider now the time series representation of $R_{t h}$. To deduce that it is an $A R M A(1,1)$, it suffices to show that $\eta_{t h}=\left(\eta_{1}(t h), \eta_{2}(t h)\right)^{\prime}$ is an $A R M A(1,1)$ for $h$ fixed. Let

$$
\zeta_{t h}=\left[\begin{array}{cc}
1-\exp \left(-\gamma_{1} h\right) L & 0 \\
0 & 1-\exp \left(-\gamma_{2} h\right) L
\end{array}\right]\left[\begin{array}{l}
\eta_{1}(t h) \\
\eta_{2}(t h)
\end{array}\right]
$$

and define:

$$
\begin{aligned}
\phi_{i} & =\exp \left(-\gamma_{i} h\right) \\
\sigma_{v_{i}}^{2} & =\left(\sigma_{i}^{b}\right)^{2} h \\
\sigma_{u_{i}}^{2} & =\left(\sigma_{i}^{a}\right)^{2} \frac{1-\exp \left(-2 \gamma_{1} h\right)}{2 \gamma_{i}} \\
\rho_{12}^{b} & =\rho_{b} \sigma_{1}^{b} \sigma_{2}^{b} h, \\
\rho_{12}^{a} & =\rho_{a} \sigma_{1}^{a} \sigma_{2}^{a} \frac{1-\exp \left(-\left(\gamma_{1}+\gamma_{2}\right) h\right)}{\gamma_{1}+\gamma_{2}}
\end{aligned}
$$

It is easily shown that:

$$
\begin{aligned}
E \zeta_{t h} \zeta_{t h}^{\prime} & =\left[\begin{array}{cc}
\left(1+\phi_{1}^{2}\right) \sigma_{v_{1}}^{2}+2 \sigma_{u_{1}}^{2} & \left(1+\phi_{1} \phi_{2}\right) \rho_{12}^{b}+2 \rho_{12}^{a} \\
\left(1+\phi_{1} \phi_{2}\right) \rho_{12}^{b}+2 \rho_{12}^{a} & \left(1+\phi_{2}^{2}\right) \sigma_{v_{2}}^{2}+2 \sigma_{u_{2}}^{2}
\end{array}\right], \\
E \zeta_{t h} \zeta_{(t-1) h}^{\prime} & =\left[\begin{array}{cc}
-\phi_{1} \sigma_{v_{1}}^{2}-\sigma_{u_{1}}^{2} & -\phi_{1} \rho_{12}^{b}-\rho_{12}^{a} \\
-\phi_{2} \rho_{12}^{b}-\rho_{12}^{a} & -\phi_{2} \sigma_{v_{2}}^{2}-\sigma_{u_{2}}^{2}
\end{array}\right]
\end{aligned}
$$

and

$$
E \zeta_{t h} \zeta_{(t-k) h}^{\prime}=0
$$

for $k \geq 2$. We conclude that $\zeta_{t h}$ is an $M A(1)$ process. Accordingly, $\eta_{t h}$ is an $A R M A(1,1)$ for any fixed $h$. This is also true for $\eta_{t h}^{*}=\eta_{t h} / h^{1 / 2}$ and we have:

$$
E\left(\eta_{i}^{*}(t h)\right)^{2}=\left(\sigma_{i}^{a}\right)^{2} \frac{1-\exp \left(-\gamma_{i} h\right)}{\gamma_{i} h}+\left(\sigma_{i}^{b}\right)^{2}
$$

and

$$
E \eta_{1}^{*}(t h) \eta_{2}^{*}(t h)=\rho_{a} \sigma_{1}^{a} \sigma_{2}^{a} \frac{2-\exp \left(-\gamma_{1} h\right)-\exp \left(-\gamma_{2} h\right)}{\left(\gamma_{1}+\gamma_{2}\right) h}+\rho_{b} \sigma_{1}^{b} \sigma_{2}^{b}
$$


When $h \rightarrow 0, \eta_{t h}^{*}$ is and i.i.d. process such that:

$$
\begin{aligned}
\eta^{*}(t h) & =v^{*}(t h)+u^{*}(t h) \\
& \sim \text { i.i.d. } N\left(0,\left[\begin{array}{cc}
\left(\sigma_{1}^{b}\right)^{2}+\left(\sigma_{1}^{a}\right)^{2} & \rho_{a} \sigma_{1}^{a} \sigma_{2}^{a}+\rho_{b} \sigma_{1}^{b} \sigma_{2}^{b} \\
\rho_{a} \sigma_{1}^{a} \sigma_{2}^{a}+\rho_{b} \sigma_{1}^{b} \sigma_{2}^{b} & \left(\sigma_{2}^{b}\right)^{2}+\left(\sigma_{2}^{a}\right)^{2}
\end{array}\right]\right) .
\end{aligned}
$$

Proof of Proposition 3: From the preceding proof, we readily obtain:

$$
\begin{aligned}
\beta_{0 h} & =\frac{\operatorname{cov}\left(R_{1}(t h), R_{2}(t h)\right)}{\operatorname{var}\left(R_{2}(t h)\right)} \\
& =\frac{\operatorname{cov}\left(\eta_{1}(t h), \eta_{2}(t h)\right)}{\operatorname{var}\left(\eta_{2}(t h)\right)} \\
& =\frac{\rho_{a} \sigma_{1}^{a} \sigma_{2}^{a} \frac{2-\exp \left(-\gamma_{1} h\right)-\exp \left(-\gamma_{2} h\right)}{\left(\gamma_{1}+\gamma_{2}\right) h}+\rho_{b} \sigma_{1}^{b} \sigma_{2}^{b}}{\left(\sigma_{2}^{a}\right)^{2} \frac{1-\exp \left(-\gamma_{2} h\right)}{\gamma_{2} h}+\left(\sigma_{2}^{b}\right)^{2}} .
\end{aligned}
$$

The limiting values when $h$ converges to 0 or $\infty$ are easily deduced. 


\section{References}

[1] Arnold, L. (1974): Stochastic Differential Equations: Theory and Applications, New York: John Wiley.

[2] Banz, R.W. (1981): "The Relationship Between Return and Market Value of Common Stocks," Journal of Financial Economics 9, 3-18.

[3] Black, F. and M. Scholes (1973): "The Pricing of Options and Corporate Liabilities," Journal of Political Economy 81, 637-659.

[4] Cohen, K., G. Hawawini, S. Maier, R. Schwartz and D. Whitcomb (1983): "Friction in The Trading Process and The Estimation of Systematic Risk," Journal of Financial Economics 12, 263-278.

[5] Corhay, A. (1990): "Effet d'Intervalle et Estimation du Risque Systématique à la Bourse de Bruxelles," Journal de la Société Statistique de Paris 131, 69-84.

[6] Defrère, N. (1995): "Effet d'Intervalle sur le Marché à Terme de la Bourse de Bruxelles," Recherches Economiques de Louvain 61, 509-526.

[7] Dimson, E. (1979): "Risk Measurement When Shares are Subject to Infrequent Trading," Journal of Financial Economics 7, 197-226.

[8] Fama, E. and K.R. French (1988): "Permanent and Temporary Components of Stock Prices," Journal of Political Economy 96, 246-273.

[9] Handa P., S.P. Kothari and C. Wasley (1989): “The Relation Between Return Interval and Betas: Implications for Size Effect," Journal of Financial Economics 23,79-100.

[10] Handa P., S.P. Kothari and C. Wasley (1993): "Sensitivity of Multivariate Tests of Capital Asset Pricing Model to The Return Measurement Interval," Journal of Finance 38, $1543-1551$.

[11] Hawawini A.G. (1980): "Intertemporal Cross-Dependence in Securities Daily Returns and The Short-Run Intervalling Effect on Systematic Risk," Journal of Financial and Quantitative Analysis 15, 139-149.

[12] Levary, D. and H. Levy (1977): "The Capital Asset Pricing Model and The Investment Horizon," Review of Economics and Statistics 59, 92-104.

[13] Lintner, J. (1965): "Security Prices and Maximal Gains from Diversification," Journal of Finance $x x, 587-616$.

[14] Merton, R. (1973): “An Intertemporal Capital Asset Pricing Model,” Economica 41, $867-888$. 
[15] Pogue, G.A. and B. H. Solnik (1974): "The Market Model Applied to European Common Stocks: Some Empirical Results," Journal of Finance and Quantitative Analysis $\mathbf{9}, 917-944$.

[16] Poterba, M.J. and H.L. Summers (1988): "Mean Reversion in Stock Prices: Evidence and Implications," Journal of Financial Economics 22, 27-59.

[17] Reinganum, M.R. (1982): "A Direct Test of Roll's Conjecture on the Firm Size Effect," Journal of Finance 37, 27-35.

[18] Roll, R. (1981): "A Possible Fxplanation of the Small Firm Size Effect," Journal of Finance 36, 879-888.

[19] Shanken, J. (1985): "Multivariate Tests of Zero-Beta CAPM," Journal of Financial Economics 14, 327-348.

[20] Sharpe, N.F. (1964): "Capital Asset Prices: A Theory of Market Equilibrium under Conditions of Risk," Journal of Finance $x x, 425-442$.

[21] Scholes, M. and J. Williams (1977): "Estimating Betas from Nonsynchronous Data," Journal of Financial Economics 5, 309-327.

[22] Smith, K. (1978): "The Effect of Intervalling on Estimating Parameters of the Capital Asset Pricing Model," Journal of Financial and Quantitative Analysis 13, 313-332. (not cited ???)

[23] Vodounou, C. (1997): Essais en économétrie théorique et en économétrie de la finance appliqués aux modèles dynamiques, Unpublished PhD Dissertation, Département de Sciences Économiques, Université de Montréal. 
Table 1: Selected parameter values

\begin{tabular}{cccccc}
\hline \hline \multicolumn{6}{c}{ Portfolio } \\
\hline & P1 & P2 & P3 & P4 & P5 \\
\hline$\rho_{a}$ & 0.6000 & 0.7000 & 0.7000 & 0.1000 & 0.6000 \\
$\sigma_{1}^{a}$ & 2.0000 & 3.0055 & 1.0309 & 1.5000 & 1.5000 \\
$\sigma_{2}^{a}$ & 1.2000 & 1.5584 & 0.5345 & 1.0000 & 1.0000 \\
& & & & & \\
$\rho_{b}$ & 0.7500 & 0.1000 & 0.6000 & 0.7000 & 0.7000 \\
$\sigma_{1}^{b}$ & 1.0000 & 1.5000 & 1.5000 & 3.0055 & 1.0309 \\
$\sigma_{2}^{b}$ & 0.7500 & 1.0000 & 1.0000 & 1.5584 & 0.5345 \\
& & & & & \\
$\widetilde{\beta}_{0 a}$ & 1.0000 & 1.3500 & 1.3500 & 0.1500 & 0.9000 \\
$\widetilde{\beta}_{0 b}$ & 1.0000 & 0.1500 & 0.9000 & 1.3500 & 1.3500 \\
& & & & & \\
& & & & & \\
\hline
\end{tabular}


Table 2: Mean and standard deviation of the estimated beta;

\begin{tabular}{|c|c|c|c|c|c|c|c|c|c|c|}
\hline & & $\mathbf{h}$ & 0 & 1 & 2 & 4 & 8 & 12 & 24 & $\infty$ \\
\hline \multirow[t]{20}{*}{ Mean } & \multirow[t]{5}{*}{$\mathrm{T}=25$} & $\overline{\mathrm{P} 1}$ & 0.993 & 1.005 & 0.994 & 1.001 & 1.000 & 0.996 & 1.001 & 1.002 \\
\hline & & P2 & 0.991 & 0.991 & 0.944 & 0.904 & 0.807 & 0.725 & 0.554 & 0.143 \\
\hline & & P3 & 0.997 & 0.997 & 0.993 & 0.977 & 0.965 & 0.947 & 0.928 & 0.901 \\
\hline & & P4 & 0.993 & 1.029 & 1.046 & 1.079 & 1.148 & 1.187 & 1.257 & 1.353 \\
\hline & & P5 & 0.991 & 1.010 & 1.017 & 1.030 & 1.069 & 1.094 & 1.163 & 1.353 \\
\hline & \multirow[t]{5}{*}{$\mathrm{T}=50$} & $\overline{\mathrm{P} 1}$ & 1.000 & 1.005 & 0.996 & 0.995 & 1.000 & 0.997 & 0.998 & 0.999 \\
\hline & & P2 & 1.002 & 0.987 & 0.945 & 0.898 & 0.810 & 0.723 & 0.548 & 0.153 \\
\hline & & P3 & 1.001 & 0.993 & 0.989 & 0.973 & 0.958 & 0.938 & 0.928 & 0.900 \\
\hline & & P4 & 1.006 & 1.023 & 1.044 & 1.079 & 1.145 & 1.180 & 1.259 & 1.349 \\
\hline & & P5 & 1.002 & 1.006 & 1.019 & 1.026 & 1.065 & 1.089 & 1.164 & 1.349 \\
\hline & \multirow[t]{5}{*}{$\mathrm{T}=100$} & $\overline{\mathrm{P} 1}$ & 0.999 & 0.999 & 1.003 & 0.999 & 1.001 & 0.996 & 1.000 & 1.002 \\
\hline & & P2 & 0.997 & 0.976 & 0.954 & 0.900 & 0.810 & 0.722 & 0.555 & 0.147 \\
\hline & & P3 & 0.999 & 0.992 & 0.989 & 0.975 & 0.958 & 0.939 & 0.927 & 0.901 \\
\hline & & P4 & 0.998 & 1.022 & 1.048 & 1.085 & 1.146 & 1.182 & 1.257 & 1.352 \\
\hline & & P5 & 0.998 & 1.005 & 1.019 & 1.031 & 1.066 & 1.090 & 1.162 & 1.352 \\
\hline & \multirow[t]{5}{*}{$\mathrm{T}=200$} & $\begin{array}{l}\text { P1 } \\
\text {. }\end{array}$ & 1.003 & 0.998 & 1.003 & 1.001 & 1.000 & 0.997 & 1.001 & 1.002 \\
\hline & & P2 & 1.002 & 0.974 & 0.952 & 0.902 & 0.809 & 0.724 & 0.556 & 0.150 \\
\hline & & P3 & 1.002 & 0.991 & 0.989 & 0.977 & 0.957 & 0.941 & 0.928 & 0.902 \\
\hline & & P4 & 1.003 & 1.021 & 1.049 & 1.089 & 1.145 & 1.183 & 1.258 & 1.352 \\
\hline & & P5 & 1.002 & 1.005 & 1.018 & 1.034 & 1.065 & 1.091 & 1.163 & 1.352 \\
\hline \multirow{20}{*}{$\begin{array}{l}\text { Standard } \\
\text { deviation }\end{array}$} & \multirow[t]{5}{*}{$\mathrm{T}=25$} & 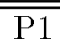 & 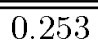 & 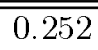 & 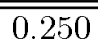 & 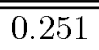 & $\bar{~} 0.245$ & 0.237 & $\overline{0.218}$ & $\bar{~} 0.191$ \\
\hline & & P2 & 0.322 & 0.328 & 0.331 & 0.335 & 0.350 & 0.348 & 0.343 & 0.320 \\
\hline & & P3 & 0.269 & 0.270 & 0.269 & 0.264 & 0.260 & 0.261 & 0.260 & 0.259 \\
\hline & & P4 & 0.322 & 0.324 & 0.321 & 0.321 & 0.316 & 0.309 & 0.302 & 0.298 \\
\hline & & P5 & 0.272 & 0.276 & 0.270 & 0.276 & 0.292 & 0.287 & 0.293 & 0.298 \\
\hline & \multirow[t]{5}{*}{$\mathrm{T}=50$} & P1 & 0.168 & 0.173 & 0.172 & 0.173 & 0.168 & 0.163 & 0.151 & 0.128 \\
\hline & & P2 & 0.219 & 0.226 & 0.225 & 0.234 & 0.242 & 0.243 & 0.236 & 0.220 \\
\hline & & P3 & 0.185 & 0.187 & 0.183 & 0.177 & 0.179 & 0.178 & 0.177 & 0.173 \\
\hline & & P4 & 0.222 & 0.224 & 0.223 & 0.215 & 0.215 & 0.212 & 0.208 & 0.200 \\
\hline & & P5 & 0.181 & 0.189 & 0.188 & 0.188 & 0.201 & 0.199 & 0.201 & 0.200 \\
\hline & \multirow[t]{5}{*}{$\mathrm{T}=100$} & P1 & 0.121 & 0.119 & 0.118 & 0.116 & 0.117 & 0.114 & 0.104 & 0.088 \\
\hline & & P2 & 0.155 & 0.155 & 0.158 & 0.160 & 0.164 & 0.168 & 0.167 & 0.152 \\
\hline & & P3 & 0.130 & 0.127 & 0.126 & 0.124 & 0.126 & 0.125 & 0.125 & 0.119 \\
\hline & & P4 & 0.155 & 0.153 & 0.152 & 0.150 & 0.151 & 0.149 & 0.146 & 0.137 \\
\hline & & P5 & 0.130 & 0.129 & 0.132 & 0.132 & 0.138 & 0.143 & 0.140 & 0.137 \\
\hline & \multirow[t]{5}{*}{$\mathrm{T}=200$} & $\mathrm{P} 1$ & 0.086 & 0.083 & 0.084 & 0.083 & 0.080 & 0.080 & 0.073 & 0.064 \\
\hline & & P2 & 0.109 & 0.109 & 0.111 & 0.114 & 0.112 & 0.117 & 0.117 & 0.105 \\
\hline & & P3 & 0.090 & 0.088 & 0.089 & 0.088 & 0.086 & 0.088 & 0.087 & 0.088 \\
\hline & & P4 & 0.110 & 0.107 & 0.107 & 0.106 & 0.104 & 0.105 & 0.102 & 0.100 \\
\hline & & P5 & 0.091 & 0.090 & 0.093 & 0.094 & 0.096 & 0.100 & 0.098 & 0.100 \\
\hline
\end{tabular}


Table 3: Mean and standard deviation of the estimated beta;

\begin{tabular}{|c|c|c|c|c|c|c|c|c|c|c|}
\hline & & $\mathrm{h}$ & 0 & 1 & 2 & 4 & 8 & 12 & 24 & $\infty$ \\
\hline \multirow[t]{20}{*}{ Mean } & \multirow[t]{5}{*}{$\mathrm{T}=25$} & $\overline{\mathrm{P} 1}$ & 0.993 & 1.005 & 1.002 & 1.000 & 1.006 & 1.002 & 1.002 & 1.002 \\
\hline & & P2 & 0.991 & 0.934 & 0.857 & 0.724 & 0.555 & 0.458 & 0.331 & 0.143 \\
\hline & & P3 & 0.997 & 0.983 & 0.970 & 0.947 & 0.934 & 0.919 & 0.911 & 0.901 \\
\hline & & $\mathrm{P} 4$ & 0.993 & 1.072 & 1.120 & 1.185 & 1.262 & 1.286 & 1.318 & 1.353 \\
\hline & & P5 & 0.991 & 1.027 & 1.049 & 1.094 & 1.168 & 1.203 & 1.264 & 1.353 \\
\hline & \multirow[t]{5}{*}{$\mathrm{T}=50$} & $\overline{\mathrm{P} 1}$ & 1.000 & 1.001 & 1.002 & 0.995 & 1.001 & 0.996 & 1.002 & 0.999 \\
\hline & & P2 & 1.002 & 0.927 & 0.856 & 0.724 & 0.552 & 0.448 & 0.330 & 0.153 \\
\hline & & P3 & 1.001 & 0.980 & 0.966 & 0.944 & 0.927 & 0.912 & 0.911 & 0.900 \\
\hline & & P4 & 1.006 & 1.065 & 1.117 & 1.183 & 1.257 & 1.279 & 1.319 & 1.349 \\
\hline & & P5 & 1.002 & 1.022 & 1.050 & 1.089 & 1.162 & 1.196 & 1.264 & 1.349 \\
\hline & \multirow[t]{5}{*}{$\mathrm{T}=100$} & $\mathrm{P} 1$ & 0.999 & 1.000 & 1.002 & 1.000 & 1.001 & 0.996 & 1.000 & 1.002 \\
\hline & & $\mathrm{P} 2$ & 0.997 & 0.927 & 0.855 & 0.725 & 0.553 & 0.450 & 0.327 & 0.147 \\
\hline & & P3 & 0.999 & 0.980 & 0.967 & 0.946 & 0.927 & 0.912 & 0.910 & 0.901 \\
\hline & & P4 & 0.998 & 1.065 & 1.121 & 1.189 & 1.257 & 1.279 & 1.318 & 1.352 \\
\hline & & P5 & 0.998 & 1.022 & 1.051 & 1.094 & 1.163 & 1.198 & 1.263 & 1.352 \\
\hline & \multirow[t]{5}{*}{$\mathrm{T}=200$} & $\mathrm{P} 1$ & 1.003 & 0.999 & 1.003 & 1.002 & 1.000 & 0.997 & 1.001 & 1.002 \\
\hline & & P2 & 1.002 & 0.924 & 0.854 & 0.727 & 0.553 & 0.452 & 0.329 & 0.150 \\
\hline & & P3 & 1.002 & 0.978 & 0.967 & 0.947 & 0.925 & 0.914 & 0.911 & 0.902 \\
\hline & & P4 & 1.003 & 1.064 & 1.122 & 1.192 & 1.255 & 1.281 & 1.318 & 1.352 \\
\hline & & P5 & 1.002 & 1.022 & 1.050 & 1.096 & 1.162 & 1.199 & 1.264 & 1.352 \\
\hline \multirow{20}{*}{$\begin{array}{l}\text { Standard } \\
\text { deviation }\end{array}$} & \multirow[t]{5}{*}{$\mathrm{T}=25$} & 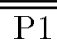 & 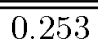 & 0.254 & $\overline{0.242}$ & 0.235 & 0.217 & $\overline{0.206}$ & 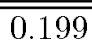 & $\bar{~} 0.191$ \\
\hline & & P2 & 0.322 & 0.338 & 0.337 & 0.348 & 0.338 & 0.335 & 0.332 & 0.320 \\
\hline & & P3 & 0.269 & 0.268 & 0.268 & 0.261 & 0.255 & 0.258 & 0.257 & 0.259 \\
\hline & & $\mathrm{P} 4$ & 0.322 & 0.322 & 0.319 & 0.314 & 0.302 & 0.300 & 0.295 & 0.298 \\
\hline & & P5 & 0.272 & 0.281 & 0.282 & 0.289 & 0.292 & 0.287 & 0.291 & 0.298 \\
\hline & \multirow[t]{5}{*}{$\mathrm{T}=50$} & P1 & 0.168 & 0.173 & 0.166 & 0.158 & 0.150 & 0.143 & 0.137 & 0.128 \\
\hline & & P2 & 0.219 & 0.231 & 0.234 & 0.233 & 0.233 & 0.228 & 0.225 & 0.220 \\
\hline & & P3 & 0.185 & 0.186 & 0.183 & 0.175 & 0.175 & 0.174 & 0.174 & 0.173 \\
\hline & & $\mathrm{P} 4$ & 0.222 & 0.223 & 0.219 & 0.210 & 0.205 & 0.205 & 0.202 & 0.200 \\
\hline & & P5 & 0.181 & 0.193 & 0.196 & 0.195 & 0.200 & 0.199 & 0.200 & 0.200 \\
\hline & \multirow[t]{5}{*}{$\mathrm{T}=100$} & $\mathrm{P} 1$ & 0.121 & 0.118 & 0.116 & 0.110 & 0.104 & 0.101 & 0.095 & 0.088 \\
\hline & & P2 & 0.155 & 0.157 & 0.165 & 0.166 & 0.163 & 0.163 & 0.158 & 0.152 \\
\hline & & P3 & 0.130 & 0.126 & 0.125 & 0.122 & 0.123 & 0.122 & 0.123 & 0.119 \\
\hline & & P4 & 0.155 & 0.152 & 0.151 & 0.146 & 0.144 & 0.143 & 0.142 & 0.137 \\
\hline & & P5 & 0.130 & 0.131 & 0.137 & 0.138 & 0.139 & 0.141 & 0.140 & 0.137 \\
\hline & \multirow[t]{5}{*}{$\mathrm{T}=200$} & $\mathrm{P} 1$ & 0.086 & 0.083 & 0.083 & 0.078 & 0.072 & 0.071 & 0.067 & 0.064 \\
\hline & & P2 & 0.109 & 0.112 & 0.115 & 0.116 & 0.112 & 0.114 & 0.110 & 0.105 \\
\hline & & P3 & 0.090 & 0.088 & 0.088 & 0.087 & 0.085 & 0.087 & 0.086 & 0.088 \\
\hline & & P4 & 0.110 & 0.106 & 0.107 & 0.103 & 0.100 & 0.101 & 0.099 & 0.100 \\
\hline & & P5 & 0.091 & 0.092 & 0.097 & 0.098 & 0.096 & 0.099 & 0.098 & 0.100 \\
\hline
\end{tabular}


Table 4: Mean and standard deviation of the estimated beta;

\begin{tabular}{|c|c|c|c|c|c|c|c|c|c|c|}
\hline & & $\mathrm{h}$ & 0 & 1 & 2 & 4 & 8 & 12 & 24 & $\infty$ \\
\hline \multirow{20}{*}{ Mean } & \multirow[t]{5}{*}{$\mathrm{T}=25$} & $\overline{\mathrm{P} 1}$ & 0.993 & 1.002 & 1.003 & 0.999 & 1.006 & 1.000 & 1.001 & 1.002 \\
\hline & & P2 & 0.991 & 1.003 & 1.000 & 0.992 & 0.999 & 0.993 & 0.980 & 0.143 \\
\hline & & P3 & 0.997 & 1.001 & 1.005 & 1.000 & 1.006 & 0.997 & 0.997 & 0.901 \\
\hline & & P4 & 0.993 & 1.010 & 1.006 & 0.998 & 1.011 & 1.008 & 1.029 & 1.353 \\
\hline & & P5 & 0.991 & 1.003 & 1.003 & 0.999 & 1.008 & 1.004 & 1.009 & 1.353 \\
\hline & \multirow[t]{5}{*}{$\mathrm{T}=50$} & $\overline{\mathrm{P} 1}$ & 1.000 & 1.001 & 1.003 & 0.995 & 1.001 & 0.995 & 1.001 & 0.999 \\
\hline & & P2 & 1.002 & 1.000 & 1.002 & 0.992 & 0.994 & 0.983 & 0.975 & 0.153 \\
\hline & & P3 & 1.001 & 1.000 & 1.002 & 0.996 & 1.000 & 0.988 & 0.995 & 0.900 \\
\hline & & P4 & 1.006 & 1.002 & 1.002 & 0.997 & 1.007 & 1.002 & 1.030 & 1.349 \\
\hline & & P5 & 1.002 & 1.000 & 1.004 & 0.997 & 1.004 & 0.999 & 1.009 & 1.349 \\
\hline & \multirow[t]{5}{*}{$\mathrm{T}=100$} & $\overline{\mathrm{P} 1}$ & 0.999 & 0.998 & 1.003 & 0.999 & 1.001 & 0.996 & 1.001 & 1.002 \\
\hline & & P2 & 0.997 & 0.999 & 1.001 & 0.995 & 0.994 & 0.985 & 0.973 & 0.147 \\
\hline & & P3 & 0.999 & 0.999 & 1.003 & 1.000 & 0.999 & 0.990 & 0.994 & 0.901 \\
\hline & & P4 & 0.998 & 1.000 & 1.005 & 1.004 & 1.010 & 1.007 & 1.030 & 1.352 \\
\hline & & P5 & 0.998 & 0.998 & 1.003 & 1.001 & 1.005 & 1.002 & 1.010 & 1.352 \\
\hline & \multirow[t]{5}{*}{$\mathrm{T}=200$} & P1 & 1.003 & 0.998 & 1.003 & 1.000 & 1.001 & 0.998 & 1.001 & 1.002 \\
\hline & & P2 & 1.002 & 0.997 & 0.999 & 0.995 & 0.993 & 0.986 & 0.975 & 0.150 \\
\hline & & P3 & 1.002 & 0.998 & 1.003 & 1.001 & 0.998 & 0.992 & 0.994 & 0.902 \\
\hline & & P4 & 1.003 & 0.999 & 1.006 & 1.007 & 1.009 & 1.010 & 1.030 & 1.352 \\
\hline & & P5 & 1.002 & 0.998 & 1.003 & 1.002 & 1.005 & 1.004 & 1.011 & 1.352 \\
\hline \multirow{20}{*}{$\begin{array}{l}\text { Standard } \\
\text { Deviation }\end{array}$} & \multirow[t]{5}{*}{$\mathrm{T}=25$} & 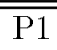 & 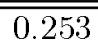 & $\overline{0.255}$ & $\overline{0.244}$ & 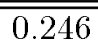 & $\overline{0.249}$ & 0.248 & $\overline{0.252}$ & 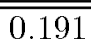 \\
\hline & & P2 & 0.322 & 0.328 & 0.315 & 0.321 & 0.320 & 0.323 & 0.335 & 0.320 \\
\hline & & P3 & 0.269 & 0.270 & 0.269 & 0.267 & 0.264 & 0.266 & 0.270 & 0.259 \\
\hline & & P4 & 0.322 & 0.322 & 0.321 & 0.323 & 0.325 & 0.322 & 0.322 & 0.298 \\
\hline & & P5 & 0.272 & 0.272 & 0.263 & 0.262 & 0.269 & 0.270 & 0.274 & 0.298 \\
\hline & \multirow[t]{5}{*}{$\mathrm{T}=50$} & $\mathrm{P} 1$ & 0.168 & 0.176 & 0.169 & 0.168 & 0.173 & 0.170 & 0.169 & 0.128 \\
\hline & & P2 & 0.219 & 0.224 & 0.218 & 0.218 & 0.217 & 0.219 & 0.225 & 0.220 \\
\hline & & P3 & 0.185 & 0.188 & 0.184 & 0.179 & 0.181 & 0.181 & 0.183 & 0.173 \\
\hline & & $\mathrm{P} 4$ & 0.222 & 0.225 & 0.224 & 0.217 & 0.220 & 0.219 & 0.220 & 0.200 \\
\hline & & P5 & 0.181 & 0.187 & 0.183 & 0.179 & 0.185 & 0.184 & 0.184 & 0.200 \\
\hline & \multirow[t]{5}{*}{$\mathrm{T}=100$} & $\overline{\mathrm{P} 1}$ & 0.121 & 0.119 & 0.118 & 0.117 & 0.120 & 0.121 & 0.119 & 0.088 \\
\hline & & P2 & 0.155 & 0.153 & 0.153 & 0.153 & 0.153 & 0.157 & 0.160 & 0.152 \\
\hline & & P3 & 0.130 & 0.127 & 0.126 & 0.126 & 0.128 & 0.129 & 0.129 & 0.119 \\
\hline & & P4 & 0.155 & 0.153 & 0.153 & 0.151 & 0.154 & 0.155 & 0.154 & 0.137 \\
\hline & & P5 & 0.130 & 0.128 & 0.128 & 0.125 & 0.129 & 0.131 & 0.130 & 0.137 \\
\hline & \multirow[t]{5}{*}{$\mathrm{T}=200$} & $\mathrm{P} 1$ & 0.086 & 0.083 & 0.083 & 0.084 & 0.083 & 0.085 & 0.084 & 0.064 \\
\hline & & P2 & 0.109 & 0.108 & 0.108 & 0.108 & 0.105 & 0.110 & 0.112 & 0.105 \\
\hline & & P3 & 0.090 & 0.088 & 0.089 & 0.090 & 0.088 & 0.090 & 0.090 & 0.088 \\
\hline & & P4 & 0.110 & 0.107 & 0.108 & 0.107 & 0.106 & 0.109 & 0.108 & 0.100 \\
\hline & & P5 & 0.091 & 0.089 & 0.090 & 0.090 & 0.089 & 0.092 & 0.092 & 0.100 \\
\hline
\end{tabular}


Table 5: Effect of the mean-reversion coefficients on the mean and standard deviation of the estimated beta

\begin{tabular}{|c|c|c|c|c|c|c|c|c|c|}
\hline & $\mathbf{h}$ & 0 & 1 & 2 & 4 & 8 & 12 & 24 & $\infty$ \\
\hline \multicolumn{10}{|c|}{ Mean } \\
\hline \multicolumn{10}{|c|}{$\gamma_{1}=0.01 \quad \gamma_{2}=0.20$} \\
\hline & $\mathrm{T}=25$ & 0.991 & 0.993 & 0.973 & 0.926 & 0.859 & 0.787 & 0.640 & 0.143 \\
\hline & 50 & 1.002 & 0.985 & 0.968 & 0.919 & 0.848 & 0.772 & 0.638 & 0.153 \\
\hline & 100 & 0.997 & 0.981 & 0.964 & 0.920 & 0.843 & 0.771 & 0.632 & 0.147 \\
\hline & 200 & 1.002 & 0.978 & 0.961 & 0.921 & 0.843 & 0.771 & 0.630 & 0.150 \\
\hline \multicolumn{10}{|c|}{$\gamma_{1}=0.60 \quad \gamma_{2}=0.20$} \\
\hline & $\mathrm{T}=25$ & 0.991 & 0.868 & 0.758 & 0.614 & 0.484 & 0.421 & 0.332 & 0.143 \\
\hline & 50 & 1.002 & 0.859 & 0.758 & 0.613 & 0.482 & 0.414 & 0.333 & 0.153 \\
\hline & 100 & 0.997 & 0.858 & 0.756 & 0.615 & 0.483 & 0.416 & 0.330 & 0.147 \\
\hline & 200 & 1.002 & 0.856 & 0.754 & 0.617 & 0.483 & 0.417 & 0.332 & 0.150 \\
\hline \multicolumn{10}{|c|}{$\gamma_{1}=3 \quad \gamma_{2}=0.20$} \\
\hline & $\mathrm{T}=25$ & 0.991 & 0.417 & 0.279 & 0.202 & 0.171 & 0.164 & 0.162 & 0.143 \\
\hline & 50 & 1.002 & 0.408 & 0.280 & 0.205 & 0.171 & 0.159 & 0.162 & 0.153 \\
\hline & 100 & 0.997 & 0.410 & 0.278 & 0.204 & 0.172 & 0.162 & 0.161 & 0.147 \\
\hline & 200 & 1.002 & 0.409 & 0.277 & 0.206 & 0.173 & 0.163 & 0.162 & 0.150 \\
\hline \multicolumn{10}{|c|}{ Standard deviation } \\
\hline \multirow[t]{5}{*}{$\gamma_{1}=0.01$} & $\gamma_{2}=0.20$ & & & & & & & & \\
\hline & $\mathrm{T}=25$ & 0.322 & 0.337 & 0.342 & 0.374 & 0.426 & 0.463 & 0.552 & 0.320 \\
\hline & 50 & 0.219 & 0.232 & 0.237 & 0.256 & 0.289 & 0.315 & 0.374 & 0.220 \\
\hline & 100 & 0.155 & 0.159 & 0.167 & 0.179 & 0.201 & 0.223 & 0.265 & 0.152 \\
\hline & 200 & 0.109 & 0.112 & 0.117 & 0.125 & 0.138 & 0.157 & 0.183 & 0.105 \\
\hline \multicolumn{10}{|c|}{$\gamma_{1}=0.60 \quad \gamma_{2}=0.20$} \\
\hline & $\mathrm{T}=25$ & 0.322 & 0.313 & 0.296 & 0.287 & 0.282 & 0.279 & 0.294 & 0.320 \\
\hline & 50 & 0.219 & 0.215 & 0.208 & 0.196 & 0.192 & 0.190 & 0.200 & 0.220 \\
\hline & 100 & 0.155 & 0.148 & 0.147 & 0.138 & 0.134 & 0.136 & 0.140 & 0.152 \\
\hline & 200 & 0.109 & 0.105 & 0.103 & 0.098 & 0.092 & 0.096 & 0.098 & 0.105 \\
\hline \multicolumn{10}{|c|}{$\gamma_{1}=3 \quad \gamma_{2}=0.20$} \\
\hline & $\mathrm{T}=25$ & 0.322 & 0.253 & 0.233 & 0.221 & 0.232 & 0.240 & 0.270 & 0.320 \\
\hline & 50 & 0.219 & 0.178 & 0.162 & 0.153 & 0.158 & 0.164 & 0.184 & 0.220 \\
\hline & 100 & 0.155 & 0.122 & 0.113 & 0.107 & 0.110 & 0.116 & 0.128 & 0.152 \\
\hline & 200 & 0.109 & 0.086 & 0.079 & 0.074 & 0.077 & 0.082 & 0.089 & 0.105 \\
\hline
\end{tabular}


Table 5 (cont'd): Effect of the mean-reversion coefficients on the mean and standard deviation of the estimated beta

\begin{tabular}{|c|c|c|c|c|c|c|c|c|c|}
\hline & $\mathbf{h}$ & 0 & 1 & 2 & 4 & 8 & 12 & 24 & $\infty$ \\
\hline \multicolumn{10}{|c|}{ Mean } \\
\hline \multirow{5}{*}{$\gamma_{1}=0.20$} & $\gamma_{2}=0.01$ & & & & & & & & \\
\hline & $\mathrm{T}=25$ & 0.991 & 0.947 & 0.867 & 0.737 & 0.565 & 0.459 & 0.304 & 0.143 \\
\hline & 50 & 1.002 & 0.931 & 0.860 & 0.728 & 0.560 & 0.448 & 0.301 & 0.153 \\
\hline & 100 & 0.997 & 0.924 & 0.852 & 0.727 & 0.560 & 0.449 & 0.299 & 0.147 \\
\hline & 200 & 1.002 & 0.918 & 0.849 & 0.726 & 0.559 & 0.450 & 0.299 & 0.150 \\
\hline \multirow[t]{5}{*}{$\gamma_{1}=0.20$} & $\gamma_{2}=0.60$ & & & & & & & & \\
\hline & $\mathrm{T}=25$ & 0.991 & 0.983 & 0.942 & 0.858 & 0.715 & 0.606 & 0.429 & 0.143 \\
\hline & 50 & 1.002 & 0.974 & 0.939 & 0.857 & 0.711 & 0.596 & 0.429 & 0.153 \\
\hline & 100 & 0.997 & 0.972 & 0.937 & 0.857 & 0.712 & 0.596 & 0.425 & 0.147 \\
\hline & 200 & 1.002 & 0.969 & 0.936 & 0.860 & 0.712 & 0.599 & 0.426 & 0.150 \\
\hline \multirow[t]{5}{*}{$\gamma_{1}=0.20$} & $\gamma_{2}=3$ & & & & & & & & \\
\hline & $\mathrm{T}=25$ & 0.991 & 0.760 & 0.593 & 0.454 & 0.340 & 0.295 & 0.237 & 0.143 \\
\hline & 50 & 1.002 & 0.748 & 0.591 & 0.456 & 0.344 & 0.288 & 0.237 & 0.153 \\
\hline & 100 & 0.997 & 0.742 & 0.590 & 0.454 & 0.346 & 0.291 & 0.234 & 0.147 \\
\hline & 200 & 1.002 & 0.738 & 0.591 & 0.459 & 0.348 & 0.293 & 0.234 & 0.150 \\
\hline \multicolumn{10}{|c|}{ Standard deviation } \\
\hline \multirow{5}{*}{$\gamma_{1}=0.20$} & $\gamma_{2}=0.01$ & & & & & & & & \\
\hline & $\mathrm{T}=25$ & 0.322 & 0.322 & 0.301 & 0.296 & 0.279 & 0.260 & 0.240 & 0.320 \\
\hline & 50 & 0.219 & 0.219 & 0.212 & 0.202 & 0.190 & 0.177 & 0.163 & 0.220 \\
\hline & 100 & 0.155 & 0.150 & 0.149 & 0.142 & 0.134 & 0.127 & 0.116 & 0.152 \\
\hline & 200 & 0.109 & 0.107 & 0.104 & 0.101 & 0.093 & 0.089 & 0.081 & 0.105 \\
\hline \multirow[t]{5}{*}{$\gamma_{1}=0.20$} & $\gamma_{2}=0.60$ & & & & & & & & \\
\hline & $\mathrm{T}=25$ & 0.322 & 0.359 & 0.375 & 0.424 & 0.438 & 0.424 & 0.401 & 0.320 \\
\hline & 50 & 0.219 & 0.244 & 0.259 & 0.284 & 0.300 & 0.290 & 0.271 & 0.220 \\
\hline & 100 & 0.155 & 0.166 & 0.182 & 0.200 & 0.211 & 0.209 & 0.191 & 0.152 \\
\hline & 200 & 0.109 & 0.118 & 0.127 & 0.140 & 0.144 & 0.146 & 0.134 & 0.105 \\
\hline \multirow[t]{5}{*}{$\gamma_{1}=0.20$} & $\gamma_{2}=3$ & & & & & & & & \\
\hline & $\mathrm{T}=25$ & 0.322 & 0.493 & 0.539 & 0.568 & 0.531 & 0.483 & 0.430 & 0.320 \\
\hline & 50 & 0.219 & 0.337 & 0.377 & 0.380 & 0.359 & 0.330 & 0.287 & 0.220 \\
\hline & 100 & 0.155 & 0.230 & 0.266 & 0.267 & 0.253 & 0.236 & 0.202 & 0.152 \\
\hline & 200 & 0.109 & 0.163 & 0.183 & 0.186 & 0.176 & 0.166 & 0.141 & 0.105 \\
\hline
\end{tabular}


Table 6: Effect of the coefficient of the variance-covariance matrix on the mean and standard deviation of the estimated beta. Base Case: $\gamma_{1}=\gamma_{2}=0.20, \sigma_{2}^{a} / \sigma_{2}^{b}=1.558,\left(\rho_{b}, \sigma_{1}^{b}, \sigma_{2}^{b}\right)=(0.10,1.50,1.00)$, $\sigma_{2}^{a}=1.558$.

\begin{tabular}{|c|c|c|c|c|c|c|c|c|c|}
\hline & $\mathbf{h}$ & 0 & 1 & 2 & 4 & 8 & 12 & 24 & $\infty$ \\
\hline \multicolumn{10}{|c|}{ Mean } \\
\hline \multicolumn{10}{|l|}{$\rho_{a}=0.10$} \\
\hline & $\mathrm{T}=25$ & 0.966 & 1.065 & 0.926 & 0.840 & 0.763 & 0.710 & 0.563 & 0.143 \\
\hline & 50 & 1.029 & 1.011 & 0.947 & 0.866 & 0.774 & 0.722 & 0.590 & 0.153 \\
\hline & 100 & 0.970 & 0.988 & 0.933 & 0.881 & 0.781 & 0.706 & 0.576 & 0.147 \\
\hline & 200 & 1.015 & 0.971 & 0.949 & 0.906 & 0.791 & 0.716 & 0.559 & 0.150 \\
\hline \multicolumn{10}{|c|}{$\rho_{a}=0.40 \quad \sigma_{1}^{a}=5.2596$} \\
\hline & $\mathrm{T}=25$ & 0.983 & 1.001 & 0.952 & 0.888 & 0.804 & 0.727 & 0.559 & 0.143 \\
\hline & 50 & 1.007 & 0.983 & 0.955 & 0.892 & 0.803 & 0.722 & 0.563 & 0.153 \\
\hline & 100 & 0.992 & 0.977 & 0.951 & 0.897 & 0.805 & 0.721 & 0.558 & 0.147 \\
\hline & 200 & 1.005 & 0.973 & 0.952 & 0.902 & 0.806 & 0.723 & 0.557 & 0.150 \\
\hline \multicolumn{10}{|c|}{ Standard-deviation } \\
\hline \multicolumn{10}{|l|}{$\rho_{a}=0.10$} \\
\hline & $\mathrm{T}=25$ & 2.427 & 2.379 & 2.353 & 2.415 & 2.364 & 2.087 & 1.811 & 0.320 \\
\hline & 50 & 1.664 & 1.650 & 1.649 & 1.635 & 1.605 & 1.425 & 1.226 & 0.220 \\
\hline & 100 & 1.143 & 1.145 & 1.149 & 1.119 & 1.138 & 1.011 & 0.859 & 0.152 \\
\hline & 200 & 0.821 & 0.804 & 0.803 & 0.788 & 0.772 & 0.722 & 0.605 & 0.105 \\
\hline \multicolumn{10}{|c|}{$\rho_{a}=0.40 \quad \sigma_{1}^{a}=5.2596$} \\
\hline & $\mathrm{T}=25$ & 0.588 & 0.591 & 0.576 & 0.596 & 0.593 & 0.543 & 0.508 & 0.320 \\
\hline & 50 & 0.403 & 0.408 & 0.401 & 0.406 & 0.405 & 0.372 & 0.345 & 0.220 \\
\hline & 100 & 0.281 & 0.284 & 0.282 & 0.280 & 0.284 & 0.268 & 0.243 & 0.152 \\
\hline & 200 & 0.202 & 0.200 & 0.199 & 0.196 & 0.193 & 0.189 & 0.170 & 0.105 \\
\hline
\end{tabular}


Table 6 (Cont'd): Effect of the coefficients of the variance-covariance matrix on the mean and standard deviations of the estimated beta

Base Case: $\quad \gamma_{1}=\gamma_{2}=0.20, \sigma_{2}^{a} / \sigma_{2}^{b}=1.558$, $\left(\rho_{a}, \sigma_{1}^{a}, \sigma_{2}^{a}\right)=(0.70,3.005,1.558), \sigma_{2}^{b}=1.0$

\begin{tabular}{rrrrrrrrrr}
\hline & $\mathbf{h}$ & $\mathbf{0}$ & $\mathbf{1}$ & $\mathbf{2}$ & $\mathbf{4}$ & $\mathbf{8}$ & $\mathbf{1 2}$ & $\mathbf{2 4}$ & $\boldsymbol{\infty}$ \\
\hline$\rho_{b}=0.40$ & $\sigma_{1}^{b}=0.375$ & & & Mean & & & & & \\
& $\mathrm{T}=25$ & 0.966 & 0.984 & 0.958 & 0.900 & 0.813 & 0.729 & 0.554 & 0.149 \\
& 50 & 1.015 & 0.981 & 0.956 & 0.894 & 0.808 & 0.725 & 0.555 & 0.150 \\
& 100 & 0.973 & 0.976 & 0.954 & 0.899 & 0.808 & 0.723 & 0.551 & 0.150 \\
& 200 & 1.017 & 0.975 & 0.952 & 0.901 & 0.808 & 0.723 & 0.552 & 0.150 \\
$\rho_{b}=0.70$ & $\sigma_{1}^{b}=0.214$ & & & & & & & & \\
& $\mathrm{~T}=25$ & 0.964 & 0.982 & 0.958 & 0.902 & 0.812 & 0.729 & 0.552 & 0.150 \\
& 50 & 1.003 & 0.981 & 0.956 & 0.895 & 0.808 & 0.727 & 0.553 & 0.150 \\
& 100 & 0.975 & 0.976 & 0.953 & 0.899 & 0.808 & 0.723 & 0.550 & 0.150 \\
& 200 & 1.018 & 0.975 & 0.952 & 0.900 & 0.808 & 0.724 & 0.550 & 0.150 \\
\hline \hline & & & $\mathbf{S t a n d a r d}$ deviation & & & & \\
$\rho_{b}=0.40$ & $\sigma_{1}^{b}=0.375$ & & & & & & & & \\
& $\mathrm{~T}=25$ & 2.419 & 0.282 & 0.270 & 0.283 & 0.275 & 0.260 & 0.231 & 0.074 \\
50 & 1.660 & 0.190 & 0.185 & 0.193 & 0.191 & 0.178 & 0.161 & 0.049 \\
& 100 & 1.142 & 0.131 & 0.131 & 0.134 & 0.134 & 0.127 & 0.113 & 0.034 \\
$\rho_{b}=0.70$ & $\sigma_{1}^{b}=0.214$ & 0.819 & 0.093 & 0.094 & 0.094 & 0.091 & 0.088 & 0.080 & 0.025 \\
& $\mathrm{~T}=25$ & 2.420 & 0.278 & 0.266 & 0.280 & 0.272 & 0.256 & 0.224 & 0.033 \\
& 50 & 1.662 & 0.188 & 0.182 & 0.193 & 0.190 & 0.174 & 0.156 & 0.022 \\
& 100 & 1.143 & 0.130 & 0.129 & 0.133 & 0.133 & 0.124 & 0.109 & 0.015 \\
& 200 & 0.819 & 0.093 & 0.092 & 0.092 & 0.091 & 0.087 & 0.077 & 0.011 \\
\hline
\end{tabular}


Figure 1: True value of $\beta$ on as a function of $h$

$\beta_{0 b}=\beta_{00}$



$\beta_{0 b}>\beta_{0 a}$

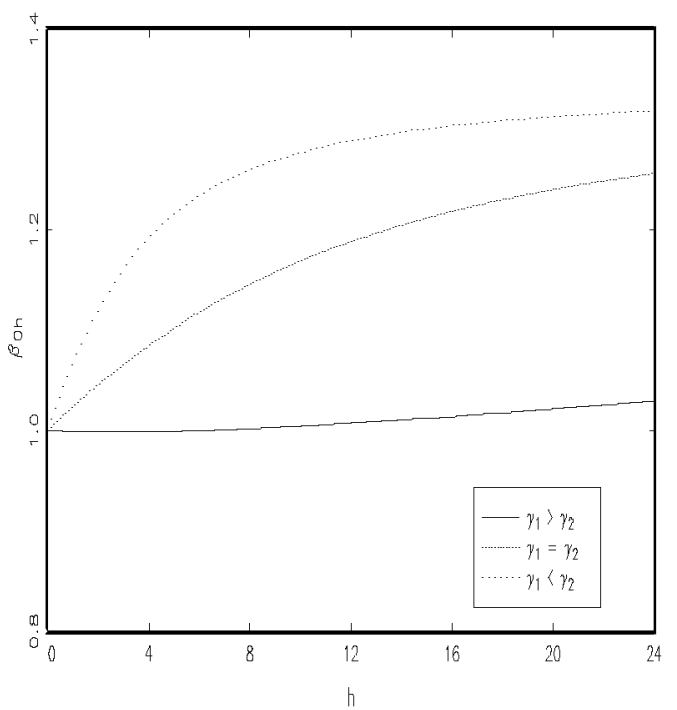

$\beta_{0 b}<\beta_{0 a}$

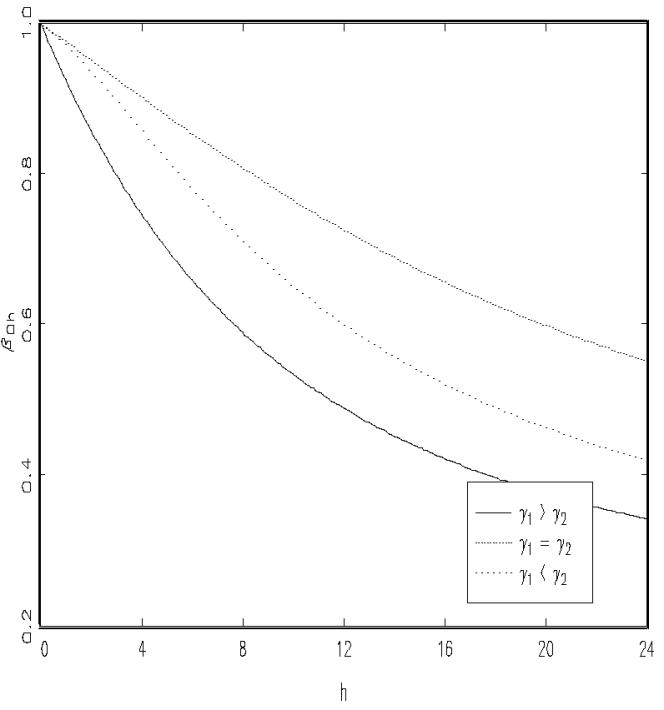

